San Jose State University

SJSU ScholarWorks

Master's Theses

Master's Theses and Graduate Research

1990

\title{
Influences of an institutional handout on the anxiety of the preliminarily diagnosed gestational diabetic
}

Bonnie Frances Coplon

San Jose State University

Follow this and additional works at: https://scholarworks.sjsu.edu/etd_theses

\section{Recommended Citation}

Coplon, Bonnie Frances, "Influences of an institutional handout on the anxiety of the preliminarily diagnosed gestational diabetic" (1990). Master's Theses. 3309.

DOI: https://doi.org/10.31979/etd.tdf8-sr5r

https://scholarworks.sjsu.edu/etd_theses/3309

This Thesis is brought to you for free and open access by the Master's Theses and Graduate Research at SJSU ScholarWorks. It has been accepted for inclusion in Master's Theses by an authorized administrator of SJSU ScholarWorks. For more information, please contact scholarworks@sjsu.edu. 


\section{INFORMATION TO USERS}

The most advanced technology has been used to photograph and reproduce this manuscript from the microfilm master. UMI films the text directly from the original or copy submitted. Thus, some thesis and dissertation copies are in typewriter face, while others may be from any type of computer printer.

The quality of this reproduction is dependent upon the quality of the copy submitted. Broken or indistinct print, colored or poor quality illustrations and photographs, print bleedthrough, substandard margins, and improper alignment can adversely affect reproduction.

In the unlikely event that the author did not send UMI a complete manuscript and there are missing pages, these will be noted. Also, if unauthorized copyright material had to be removed, a note will indicate the deletion.

Oversize materials (e.g., maps, drawings, charts) are reproduced by sectioning the original, beginning at the upper left-hand corner and continuing from left to right in equal sections with small overlaps. Each original is also photographed in one exposure and is included in reduced form at the back of the book.

Photographs included in the original manuscript have been reproduced xerographically in this copy. Higher quality 6 " $\times 9$ " black and white photographic prints are available for any photographs or illustrations appearing in this copy for an additional charge. Contact UMI directly to order.

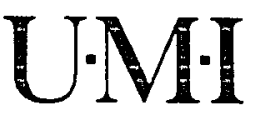

University Microfitms International

A Bell \& Howell Information Company

300 North Zeeb Road. Ann Arbor. MI 48106-1346 USA

$313 / 761-4700 \quad 800 / 521-0600$ 
$[-\ldots$

$-\cdots$ 
Order Number 1341660

Influences of an instructional handout on the anxiety of the preliminarily diagnosed gestational diabetic

Coplon, Bonnie Frances, M.P.H.

San Jose State University, 1990

$\mathrm{U} \cdot \mathrm{M} \cdot \mathrm{I}$

300 N. Zeeb Rd.

Ann Abor, MI 48106 
$\ldots+\ldots$ 


\title{
INFLUENCES OF AN INSTRUCTIONAL HANDOUT ON THE ANXIETY OF THE PRELIMINARILY DIAGNOSED GESTATIONAL DIABETIC
}

\author{
A Thesis \\ Presented to \\ The Faculty of the Department of Health Sciences \\ San Jose State University
}

In Partial Fulfillment

of the Requirements for the Degree

Master of Public Health

By

Bonnie Frances Coplon

August, 1990 
APPROVED FOR THE DEPARTMENT OF HEALTH SCIENCES

llatinlcencinilie

Kathleen Roe, Dr.P.H., MPH

Sicular fis $\psi_{0}$.

sfanley Fizip, it.p.

Neleu

Helen Ross, Ed. D.

Qde

APPROVED FOR THE UNIVERSITY

Serena Mr. Stanfore 


\begin{abstract}
INFLUENCES OF AN INSTRUCTIONAL HANDOUT ON THE ANXIETY OF THE PRELIMINARILY DIAGNOSED GESTATIONAL DIABETIC

by Bonnie Frances Coplon

The purpose of this research was to explore anxiety related to a preliminary diagnosis of Gestational Diabetes Mellitus (GDM). Specifically, this study was designed to evaluate the effectiveness of an instructional handout in decreasing anxiety at this crucial point in pregnancy and increasing positive, appropriate health beliefs.

This study was an intervention study using a preexperimental research design. A convenience sample of 25 women with a preliminary diagnosis of Gestational Diabetes was obtained from the sunnyvale Medical clinic, Sunnyvale, California between October and December, 1989. Pre- and post-test questionnaires combined assessments of anxiety (Izard, 1972) and GDM-specific health beliefs (adapted from Given, 1983).

Results indicated that anxiety was present at baseline and changed in degree and specificity after reading the instructional handout. Future study is indicated using scales that are more appropriate for this population with a corresponding time allowed for implementation of instruction.
\end{abstract}


Table of Contents

Chapter 1 - Introduction Page

Purpose............................. 3

statement of the Problem................. 3

Research Questions....................... 5

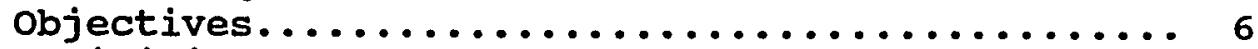

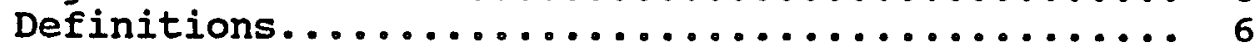

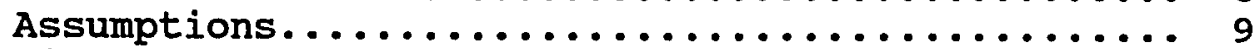

Literature Review....................... 10

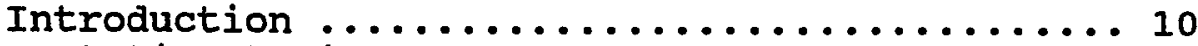

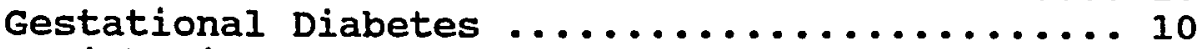

High-Risk pregnancy and Anxiety .......... 13

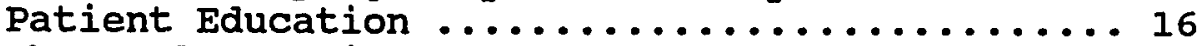

The Health Belief Model ............... 18

Compliance ....................... 21

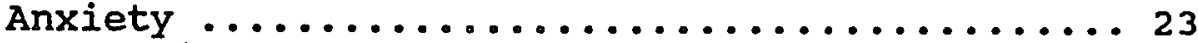

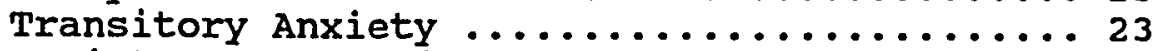

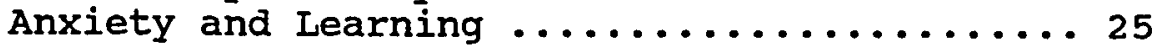

Management of Anxiety ................. 27

Self-Care ........................ 29

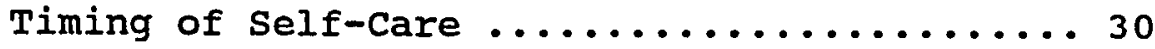

Chapter 2 - Design \& Methodology

Research Questions ................... 32

Objectives ......................... 32

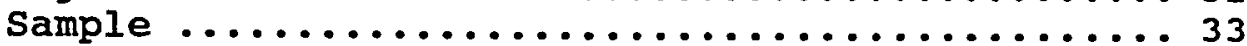

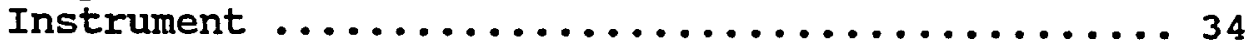

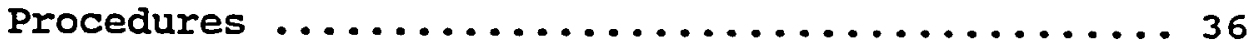

Chapter 3 - Results

Sample selection ..................... 39

Pre-Test Anxiety ...................... 41

Pre-Test Health Beliefs ................. 56

Anxiety: Differences Between

Pre- and Post-Test Scores ............. 71

Health Beliefs: Differences

Between Pre- and Post-Test Scores .........87

Summary ............................ 97

Chapter 4 - Discussion

Significance of the study ............... 98

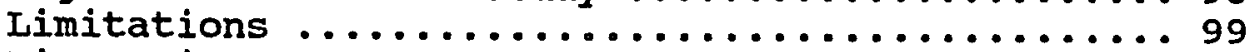

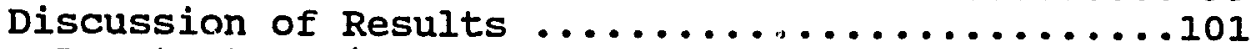

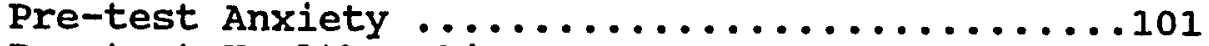

Pre-test Health Beliefs ..................104

Pre- and Post-Test Comparison of Anxiety .....105 
Pre- and Post-Test Comparison of Health

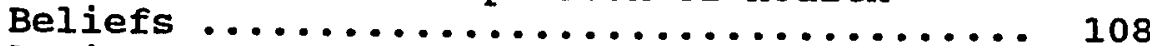

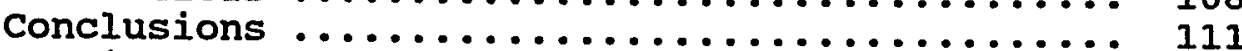

Implications for Research ................ 113

Implications for Practice ................ 114

References ............................ 117

Appendix A - DES \& A Pre-Test Questionnaire ..... 126

Appendix B - Health Belief Pre-Test Questionnaire 128

Appendix C - Site Approval Letter ............ 130

Appendix D - Human Subjects Approval Letter ..... 131

Appendix E - Consent Form .................. 132

Appendix F - Becker and Janz (1985) Organization of Health Belief clusters of Diabetic Patients (after Given et al., 1983) ................. 134

Appendix G - Text of Instructional Handout ..... 136

Appendix H Post-Test ..................... 143 


\section{List of Tables}

Table

Page

1. Pre-Test DES \& A Means and Standard Deviations for Questionnaire Items Regarding Interest

2. Pre-Test DES \& A Means and standard Deviations for Questionnaire Items Regarding Enjoyment

3. Pre-Test DES \& A Means and standard Deviations for Questionnaire Items Regarding Surprise

4. Pre-Test DES \& A Means and Standard Deviations for Questionnaire Items Regarding Distress

5. Pre-Test DES \& A Means and standard Deviations for Questionnaire Items Regarding Anger

6. Pre-Test DES \& A Means and Standard Deviations for Questionnaire Items Regarding Shyness

7. Pre-Test DES \& A Means and standard Deviations for Questionnaire Items Regarding Fear

8. Pre-Test DES \& A Means and standard Deviations for Questionnaire Items Regarding Fatigue

9. Pre-Test DES \& A Means and Standard Deviations for Questionnaire Items Regarding Calmness

10. Pre-Test DES \& A Overall Factor Means and Standard Deviations

11. Mean and Standard Deviation of Pre-Test Questionnaire Items Regarding Perceived Severity

12. Mean and Standard Deviation of Pre-Test Questionnaire Items Regarding Perceived Susceptibility

13. Mean and Standard Deviation of Pre-Test Questionnaire Items Regarding Perceived Benefits

14. Mean and Standard Deviation of Pre-Test Questionnaire Items Regarding Perceived Barriers 
15. Mean and Standard Deviation of Pre-Test Questionnaire Items Regarding Perceived Efficacy

16. Mean and Standard Deviation of Pre-Test Questionnaire Items Regarding Perceived Trust

17. Mean and Standard Deviation of Pre-Test Questionnaire Items Regarding Perceived Health Care Provider Communication

18. Pre-Test Health Belief Overall Means and Standard Deviations

19. Pre \& Post-Test Differences and T-Scores for Questionnaire Items Regarding Interest

20. Pre \& Post-Test Differences and T-Scores for Questionnaire Items Regarding Enjoyment

21. Pre \& Post-Test Differences and T-Scores for Questionnaire Items Regarding Surprise

22. Pre \& Post-Test Differences and T-Scores for Questionnaire Items Regarding Distress

23. Pre \& Post-Test Differences and T-Scores for Questionnaire Items Regarding Anger

24. Pre \& Post-Test Differences and T-Scores for Questionnaire Items Regarding Shyness

25. Pre \& Post-Test Differences and T-Scores for Questionnaire Items Regarding Fear

26. Pre \& Post-Test Differences and $T$-Scores for Questionnaire Items Regarding Fatigue

27. Pre \& Post-Test Differences and T-Scores for Questionnaire Items Regarding Calmness

28. Statistically significant Changes in overall Means From Pre- to Post-Test (DES \& A Scale)

29. Pre \& Post-Test Health Belief Cluster Differences and $T$-Scores of Questionnaire Items Regarding Perceived Severity

30. Pre \& Post-Test Health Belief Cluster Differences and $\mathrm{T}$-Scores of Questionnaire Items Regarding Perceived Susceptibility 
31. Pre \& Post-Test Health Belief cluster Differences and $\mathrm{T}$-Scores of Questionnaire Items Regarding Perceived Benefits

32. Pre \& Post-Test Health Belief Cluster Differences and $\mathrm{T}$-Scores of Questionnaire Items Regarding Perceived Barriers

33. Pre \& Post-Test Health Belief Cluster Differences and $T$-Scores of Questionnaire Items Regarding Perceived Efficacy

34. Changes in Health Beliefs Between Pre- and Post-Test 
CHAPTER 1

Introduction

Purpose

The purpose of this research was to explore the patient's experience of a preliminary diagnosis of Gestational Diabetes Mellitus (GDM). Specifically, this study was designed to evaluate the effectiveness of an instructional handout in decreasing anxiety and increasing knowledge about GDM at this crucial point in pregnancy.

statement of the Problem

Gestational Diabetes Mellitus (GDM) is a disorder of glucose intolerance observed for the first time in pregnancy. Women with GDM have an increased risk of developing diabetes in subsequent years (O'Sullivan, 1978). Research also indicates that infants of women with GDM have increased perinatal morbidity and mortality rates (Adashi, Pinto \& Tyson, 1979; Coustan \& Lewis, 1978). Gestational Diabetes Mellitus can be managea, and its effects minimized, through a daily self care regimen of blood sugar monitoring and control. Because of its potential impact on the health of both the mother and developing fetus, it is essential that GDM be recognized early and treated effectively. Effective diabetes care requires patient involvement throughout the day. Active participation by the patient is necessary in order to manage any kind of diabetes successfully. The investigator's clinical experience has 
shown that this level of involvement only occurs when the patient is fully educated in all of the areas of diabetes management that are appropriate to her care. It has been observed that this knowledge is often the motivating factor in the diabetic patient's compliance with a daily regimen. The Sunnyvale Medical clinic (SVMC) is a multispecialty health service organization accepting primarily those patients involved in HMO (Health Maintenance Organization) insurance programs. SVMC has approximately 90 physicians, 5 of whom specialize in Obstetrics and Gynecology (OB/GYN). All pregnant women treated at the sunnyvale Medical clinic are routinely screened between gestational weeks 24 and 28 with a one-hour oral glucose tolerance test (OGTT). If the test results suggest the presence of GDM, (called a preliminary GDM diagnosis), the woman is asked to return for a more definitive three-hour test. The woman, now alerted to a possible problem with her pregnancy but not given any educational information or counseling, often becomes very anxious. It is not uncommon for a sVMC patient to have to wait seven days before the second test appointment. If the second test results confirm the GDM diagnosis, the patient is instructed to make a future appointment with the Diabetes Nurse Educator. It is not until this appointment that the pregnant woman receives any formal patient education about GDM. This gap between first suggestion of a problem, 
diagnosis and education may be days. Experience has shown that during this time period, the pregnant patient becomes increasingly anxious and alarmed about GDM, its implications for her pregnancy and its impact on her own health and the health of her baby. Much of the educational session thus is spent trying to alleviate or diffuse the patient's understandable anxiety.

Decreasing the patient's anxiety is crucial for her own mental well-being, and the safety and comfort of her pregnancy. It also is essential to effective self-care instruction, and may be a significant factor in increasing compliance and minimizing the potential complications of GDM. Blood sugar control is difficult if the patient does not understand the diabetic syndrome or is overly anxious about its implications. This research was designed to explore the effectiveness of an educational intervention which could easily be incorporated into the existing structure of the SVMC.

Research Questions

1) Do women with a preliminary diagnosis of Gestational Diabetes Mellitus (GDM) experience high anxiety levels?

2) What do women with a preliminary GDM diagnosis know about Gestational Diabetes, its potential effect on their own health and its potential effect on their pregnancy?

3) Will reading an educational pamphlet on GDM during the three-hour oral glucose tolerance test decrease the 
patient's anxiety?

4) Will reading the educational pamphlet increase the patient's knowledge of GDM, its potential effect on her own health and its potential effect on her pregnancy?

objectives

This study was designed to meet the following objectives:

1) To assess the anxiety and knowledge levels of pregnant women with a preliminary diagnosis of Gestational Diabetes Mellitus.

2) To assess the effectiveness of a new educational pamphlet in decreasing anxiety levels in the preliminarily diagnosed Gestational Diabetic.

3) To develop an educational tool that can standardize clinical practice, decrease anxiety, and increase knowledge in the individual being tested for Gestational Diabetes Mellitus.

4) To develop an educational tool that will contribute to increased compliance with the self-care regimen prescribed for the Gestational Diabetic patient.

5) To decrease the potential complications of Gestational Diabetes to the mother and child.

\section{Definitions}

Concepts Operationalized in this study:

Anxiety: "The conscious and reportable experience of intense dread and foreboding, conceptualized as internally derived and unrelated to external threat" (Basowitz, Persky, 
Korchin, \& Grinkler, 1955, p.3). Pre- and post-test anxiety was measured by the combined Differential Emotion Scale and the Anxiety Scale (Izard, 1972) (Appendix A). Knowledge: Understanding of the basic GDM syndrome, particularly its potential effects on pregnancy, long-term health and the nature of self-management. Knowledge was measured by Questions $\# 1,2,3,4,6,7,8$, and 14 on the questionnaire (Appendix B).

Gestational Diabetes Mellitus: Carbohydrate intolerance of variable severity with onset or recognition during the present pregnancy measured by a three-hour oral glucose tolerance test (Coustan \& Lewis, 1978). One-Hour Oral Glucose Tolerance Test: Patient drinks 50 gram oral glucose solution with a blood sugar test performed one hour after the drink is consumed. Blood sugar levels of greater than $140 \mathrm{mg} / \mathrm{dl}$ (deciliter) are abnormal. Preliminary GDM diagnosis: Indicated when patient has failed a one-hour oral glucose tolerance test (OGTT) with a blood sugar measurement of greater than $140 \mathrm{mg} / \mathrm{dl}$. Three-Hour Oral Glucose Tolerance Test: Patient drinks 100 gram glucose solution with blood sugar tests performed at fasting, one hour, two hours, and three hours after initial drink.

Definitive GDM Diagnosis: Confirmation of the presence of Gestational Diabetes as a result of a three-hour oral glucose tolerance test (OGTT). To achieve the diagnosis of GDM, two 
out of the four blood tests must be abnormal. These blood sugar levels should be less than $105 \mathrm{mg} / \mathrm{dl}$ fasting, $190 \mathrm{mg} / \mathrm{dl}$ at one hour, $165 \mathrm{mg} / \mathrm{dl}$ at two hours and $145 \mathrm{mg} / \mathrm{dl}$ at three hours after drinking a 100 gram oral glucose solution. Concepts Central to the Framework of this study: Compliance: A decision making process. It is fulfillment by the patient of a prescribed course of treatment (Hamilton, 1983). Compliance was not measured directly in this study but would be indicated by later adherence to a regimen of daily blood sugar monitoring and control.

Standard practice: Established by custom or authority as a model, criterion or rule for comparison of measurement of a practice or phase of medicine dealing with professional diagnosis and treatment of disease (Taber, 1972). While not directly measured in this study, standard practice was used in reference to the protocols of the Sunnyvale Medical clinic.

Self-care: Ãctions taken by lay persons in their own health interest without formal medical supervision (DeFriese, . Woomert, Guild, Steckler, \& Konrad, 1989). In the case of GDM, self-care includes self blood glucose monitoring, adjusting diet, increasing exercise, and administering insulin injections. Self-care was not measured in this research but is essential to the successful management of GDM. Potential complications: Possibility of developing a complication of diabetes, i.e., macrosomia, birth trauma, and 
congenital anomalies.

\section{Assumptions}

This study was based on the following assumptions:

1) Participants would have no prior knowledge of GDM.

2) The physician or nurse would notify patients of their preliminary GDM diagnoses, and set up the test appointments without providing any other information.

3) Patients coming for the OGTT would speak and read English.

4) Patient participants would answer the survey questions truthfully.

5) Participants would read and understand the instructional handout.

6) Patients with a preliminary GDM diagnosis would be anxious about their condition.

7) Clear information about GDM would decrease anxiety.

8) Decreased anxiety will enhance compliance with the GDM self-care regimen. 


\section{Literature Review}

\section{Introduction}

The ability of the woman with Gestational Diabetes Mellitus (GDM) to understand and manage her disease is a crucial component of a successful pregnancy. Effective education enables her to learn the self-care management skills needed to avoid complications related to this disease. The investigator's clinical experience has indicated that anxiety caused by the diagnosis and fear of potential complications often interferes with the learning process and the woman's subsequent compliance. Principles of patient education, self-care education, and the health belief model (HBM) provide a useful framework for exploring anxiety and Gestational Diabetes.

\section{Gestational Diabetes}

Gestational Diabetes Mellitus (GDM) is defined by the Second International Workshop Conference of Gestational Diabetes Mellitus (1985) as carbohyarate intolerance of variable severity with onset or first recognition during the present pregnancy. This definition does not depend on the use of insulin for treatment or the condition persisting after pregnancy. Research indicates that GDM has been found to complicate from 5 - $12 \%$ of pregnancies in all gravid women (Amankwah, Prentice, \& Fleury, 1977; Coustan, Widness, Carpenter, Pratt, \& Oh, 1986; Forsbach, Contreras-Soto, Fong, Flores, \& Moreno, 1988; Macupa, 1986). 
Women with Gestational Diabetes Mellitus have a greater risk of developing diabetes in subsequent years (Grant, Oats, \& Beischer, 1986; O'Sullivan, 1978). Frienkel and Metzger (1983) found an elevated oral Glucose Tolerance Test (OGTT), a key indicator of GDM, in $57 \%$ of their gestational diabetic sample at one-year follow-up. Farrell et al. (1986) similarly found the frequency of development of abnormal glucose tolerance within 12 months of a pregnancy complicated by GDM to be much higher than had been previously thought. The occurrence of congenital malformations has been noted to be increased in infants of GDM mothers (Pederson, 1978; Plehwe, Storey, Shearman, \& Turtle, 1984). However, a distinction needs to be made between pre-pregnancy diabetes and those pregnancies complicated by diabetes (GDM). The report of the Second International Workshop conference on Gestational Diabetes Mellitus (1985) suggested that an increased incidence of congenital anomalies may reflect periconceptual metabolic abnormalities due to Diabetes Mellitus that antedated the pregnancy. Gestational Diabetes usually does not occur until the end of the second trimester or the beginning of the third, and therefore appears to pose less of a risk for complications that occur in the early gestational period (Farrell et al., 1986; Mills, 1982; Oats \& Beischer, 1985).

Research has found perinatal mortality and morbidity to be increased in women with GDM (Adashi et al., 1979). These 
pregnancies have shown a significant increase in the incidence of macrosomic infants (birth weight greater than or equal to 4000 grams) and "large for gestational age infants" (greater than or equal to $90 \%$ or two or more standard deviations above normal for weight) (Coustan \& Imahar, 1984; Gabbe, Mestman, Freeman, Anderson, \& Lowensohn, 1977; Lavin, Barden, \& Miodovinik, 1983; Miller, 1983). Macrosomia is associated with an increased occurrence of traumatic vaginal deliveries as well as an increased Caesarean section rate which can cause significant neonatal and maternal morbidity (Coustan \& Lewis, 1978; Gabbe et al., 1977; Philipson \& Super, 1989). Perinatal mortality has been estimated to occur in 5 - $19 \%$ of pregnancies among uncontrolled diabetics (Braveman et al., 1988; Gabbe et al., 1977; Macupa, 1986). However, this complication has been found at lower rates in other studies (Hoet, 1980; Lavin, Lovelace, Miodovinick, Knowles, \& Barden, 1983).

The infant of the mother with GDH is at increased risk for several other neonatal morbidities including hypoglycemia, hypocalcemia, polycythemia, and hyperbilirubinemia. In some studies, up to $25 \%$ of such offspring have been reported to suffer from these complications (Coustan et al., 1986). These figures indicate why the diagnosis of Gestational Diabetes Mellitus (GDM) labels a pregnancy high risk. Very little research has been done to discover the psychological impact of GDM or the impact of even a preliminary diagnosis 
on the pregnant woman. Most of what is known about the psychological impact of diabetes during pregnancy comes from research done on individuals who had diabetes (overt diabetes) prior to becoming pregnant. These studies have yielded contradictory findings. One study, for example, examined a group of 100 overt diabetics during their second trimester (Barglow, Hatcher, Edidin, \& Sloan-Rossiter, 1984). They found that anxiety and depression were significantly increased. In another study, specific to the psychological impact of Gestational Diabetes, Spirito et al. (1989) compared women with GDM to a non-diabetic control group. They found no significant differences between the two groups when emotional state was measured by the Profile of Mood States (Lorr \& McNire, 1982). However, it has been the experience of this investigator that the diagnosis of GDM and the knowledge that the patient now has a high-risk pregnancy does increase her anxiety, particularly in the immediate aftermath of the diagnosis. High-Risk Pregnancy and Anxiety

Any high-risk pregnancy can cause maternal anxiety. A high-risk pregnancy is defined as any gestation in which the prospects of an optimal outcome for the mother or child are decreased (Heins \& Keane, 1981). Synder (1979) suggests that a high-risk pregnancy is complex because the women must cope with two distinct crisis situations: the normal developmental crisis of childbearing as well as the recognition that the 
pregnancy may not progress along "normal" patterns or end with a healthy mother-infant dyad. As a result of this condition, the mother's abilities to cope are extremely taxed and anxiety often results.

A high-risk mother must deal with a network of problems that are physiological, psychological and societal in nature and experience. Rubin (1976) emphasizes the importance of understanding the multi-dimensional experience of high-risk childbearing. Physiologically, the woman's body is changing, adapting to the growing child inside. This leads to a vast array of emotional responses and alterations in body function. In the high-risk situation, the termination of pregnancy with a healthy full-term baby is in doubt and the health of the mother may be threatened. Inevitably, her coping mechanisms are altered as she learns to deal with the normal stresses of pregnancy and these new ones as well. Psychologically, even a normal pregnancy can cause anxiety and chalienge the woman's coping mechanisms. In addition to dealing with the physiological dimension of pregnancy, the pregnant woman's self concept often changes. Synder (1979) has labeled this as a change in the woman's "self system" and feels that a great deal of emotional work must be accomplished as she incorporates the experience of pregnancy into her "self system." A challenge in the pregnancy may have a great impact on her "self system." Galloway (1976) and Jones (1979) also discussed the emotional 
impact of a high-risk pregnancy. The woman who has problems with pregnancy may feel she is a failure as a woman, and experience guilt and feelings of punishment (SchroederZwelling \& Hock, 1986).

Finally, the societal system is where the childbearing experience occurs. This system involves those individuals around the pregnant woman and their effects upon her. The diagnosis of a high-risk pregnancy inevitably alters how significant others, i.e., her spouse, peer group, family members and friends, respond to her. In addition, the health care team may establish a different attitude and regimen with a woman whose pregnancy is officially defined as "high risk." The behavior of these key players may be quite different than it was when the pregnancy was considered "normal."

These system changes can result in anxiety. The multidimensional perspective on pregnancy presents a great challenge to the health care professionals responsible for the pregnant woman's care. It also provides insight into the problems related to a high-risk pregnancy. One of the most important problems may be increased anxiety which ultimately can affect the mother's health, the quality and impact of patient education and her ability to care for her condition. 


\section{Patient Education}

Patient education has been defined by Dunn (1988) as increased learning by the patient to act upon available information in a responsible, dependable, productive way. Nersesian and Zaremba (1982) found that nearly $20 \%$ of hospital admissions were a direct result of a lack of patient education in self-care management. Other research reported a reduced rate of hospitalization for complications in two settings in which educational interventions were an important component of care (Davidson, Alogna, Goldsmith, \& Riley, 1974) .

Education, if performed properly, is one of the many elements that contribute to improved diabetes status. Numerous studies have demonstrated the effectiveness of diabetes education in reducing the frequency of acute metabolic deterioration (Dunn, 1986; Lockington, Powles, Meadows, \& Wise, 1989; Macupa, 1986; Mazzuca et al., 1986; Miller \& Goldstein, 1972; Raz, Soskoline, \& Stein, 1988). However, other studies have found no significant improvement in glycemic control despite patient education (Howard, Barnett, Chon, \& Wolf, 1986; Miller, Goldstein, \& Nicolaisen, 1978) .

There are five widely accepted learning principles that allow for effective patient education (Dunn, 1986; Mikhail, 1981; Rosenstock, 1985). The first patient education principle is that patients must understand the situation and 
believe that the benefits of following the regimen outweigh the associated costs. It is generally understood that all clients bring into any given situation their own beliefs, motives, knowledge and experiences. These often are seen by health care professionals as either correct and appropriate or incorrect and inappropriate (Rosenstock, 1985). The client must be provided with basic knowledge regarding the nature, rationale for treatment and consequences of the condition in order to follow the established regimen. The second principle is that learning occurs most effectively when it is provided on an incremental basis where the learner acquires knowledge over time. The third principle is that behaviors that are rewarded or reinforced will be repeated and those that are ignored will be forgotten. Fourth, many behaviors have occurred for a long period of time and are often difficult to change. And finally, learning a new behavior requires both cognitive and skill development.

Patient education, the primary prescribed tool of Gestational Diabetes, must incorporate all five learning principles. This investigator has found that the patient's beliefs at the point of a GDM diagnosis often create such anxiety that effective patient education can not occur until those beliefs and the related anxiety have been resolved. 


\section{The Health Belief Model}

Effective control of diabetes has been correlated with patient participation in the disease-management process (Given, Given, Gallin, \& Condon, 1983). A useful way of understanding problems related to patient education and subsequent compliance is the health belief model (HBM) which forms the conceptual framework for this study. The HBM is based upon the value an individual places on the identified goal and the likelihood that compliance will achieve that goal (Maiman, Becker, Kirscht, Haefner, \& Drachman, 1977). According to the HBM, in order for patients to participate in the management of their disease they must have: a) conviction of susceptibility or vulnerability to the disease, b) conviction of the severity or consequences of the disease, c) belief in the efficacy and feasibility of the prescribed therapy, and d) belief that barriers to the successful execution of therapeutic behaviors can be surmounted (Cerkoney \& Hart, 1980; Given et al., 1983). Barriers may include the perception that an action may be expensive, dangerous (e.g., side effects), unpleasant (e.g., painful, difficult), inconvenient, time consuming, etc. (Becker \& Janz, 1985).

Studies have evaluated each health belief variable in terms of its potential effects on compliance. Adherence to therapeutic regimens has been found to be positively correlated with perception of susceptibility or 
resusceptibility to illness (Mikhail, 1981). Other research demonstrates a similar relationship between perception of susceptibility and compliance with an antihypertensive drug regimen (Kirscht \& Rosenstock, 1977).

A high degree of perceived severity has been positively associated with compliance with medications and other health regimens and with keeping follow-up appointments. Leventhal (1970) felt that inducing a high perceived severity through fear communication is effective in influencing health related beliefs (HRB) when the individual is provided with specific instructions on how to cope with the threat or reduce the danger. However, if perceived severity is too high the individual will find it difficult to cope and, as a defense mechanism, may engage in denial rather than taking appropriate action.

People also are more likely to comply with a variety of health recommendations if they believe that the recommended action will be effective in preventing, detecting, or treating the disease and thus reduce its threat to them (Becker \& Janz, 1985; Haefner \& Kirscht, 1970; Leavitt, 1979; Rosenstock, 1985). Perceived costs are important to evaluate. If an action is painful, inaccessible, or inconvenient, an individual is less likely to take it (Becker et al., 1978; Kirscht \& Rosenstock, 1979).

Rosenstock (1985) proposed that a fifth component should be added to effectively increase the correlation between 
compliance and some or all of the four health beliefs. This fifth component, derived from the social learning theory proposed by Bandura in 1977, is that of self-efficacy or the conviction that one is capable of carrying out specific health recommendations. Self-efficacy expectancies represent an individual's assessment of his or her potential for having the ability to perform a particular behavior (Manning \& Wright, 1983) . A large body of empirical evidence strongly suggests that perceived self-efficacy facilitates adaptive behavior and helps to mediate constructive behavior change (Bandura, 1986).

Becker et al. (1978) revised the original health belief model, directed at preventive actions taken in the absence of compelling symptoms, to help explain compliance with medical regimens after the illness has been diagnosed. The expanded model includes: 1) general health motivations based on measures of health concerns, practices, and beliefs about prevention that are primarily nonspecific and stable across situations, 2) susceptibility to illness previously contracted, including the condition under study, 3) general faith in physicians, nurses, and medical care, and 4) characteristics of the regimen which might impair compliance. Baric (1969) and Kasl (1974) proposed the relevance of being "at risk" which may lead to beliefs and behaviors different from those of individuals who have been labeled sick or healthy. This expanded definition is particularly applicable 
to the Gestational Diabetic who may feel no symptoms other than those of a normal pregnancy, but actually is at risk for complications to herself and the baby.

In summary, a large body of research supports the health belief model's potential utility in predicting a wide variety of health related behaviors ranging from participation in screening (Becker et al., 1978) and immunization programs (Leavitt, 1979) to compliance with short (Becker et al., 1985) and long term (Maiman et al., 1977) medication therapies specifically related to Diabetes Mellitus. This model has yet to be used to explore Gestational Diabetes and the psychosocial factors related to the pregnant woman's compliance. Due to the very real problems associated with uncontrolled GDM, this model was selected as the conceptual framework for this study.

\section{Compliance}

Compliance can be viewed as both an attitude and a behavior (Schlenk \& Hart, 1984). Compliance as an attitude is the willingness to follow positive health regimens while the behavior relates to the carrying out of the prescribed regimen (Davis, 1967). Non-compliance includes reluctance, reactance and recidivism that is often characterized by disinterest, refusal to comply or lack of sustained effort to follow the prescribed health regimen (Arakelian, 1980). Becker and Janz (1985) pointed out that the relationship between health beliefs and compliance is at least partly 
directional, with health beliefs becoming congruent with actual compliance as well as the reverse of this.

In his review of compliance literature, sackett (1976) noted the following trends: patients with symptoms tend to have higher compliance levels; compliance with short-term regimens decreases rapidly from day to day; and the compliance level of patients with long term therapy is about 50\%. Rosenstock (1985) reported that compliance is positively associated with the occurrence of symptoms, with continuity of care, with beliefs about the efficacy of treatment, knowledge of the nature and rationale of the prescribed regimen and the individual's social support. Alogna (1980) found that the patient's perception of severity of the illness is related to medical compliance. These factors can be assessed as early as the preliminary GDM diagnosis.

And finally, Hulka, Kuper, Cassel, and Mayo (1975) suggested that compliance is a function of the physician patient relationship. If this is so, intervention should improve communication and thus increase compliance. Rosenstock (1985) found evidence that medical care that unites providers in a therapeutic alliance is associated with better compliance.

There are certain situational demands that occur in the individual with diabetes that can affect compliance in a negative way. These include the complexity of the required 
regimen, the length of the treatment, and the interference of other habitual or desirable actions (Rosenstock, 1985). Kasl (1974) found that anxiety seems to interact with many other variables and sometimes triggers positive action while at other times it inhibits it. This situation is further complicated by the diagnosis of Gestational Diabetes and the multi-dimensional challenge of a high-risk pregnancy. In the author's experience as a health educator, anxiety is the key block to education, compliance and general well-being in the woman with GDM, particularly as she waits for a definitive diagnosis of this condition.

\section{Anxiety}

Anxiety is a psychological and physical threat to self concept (Miesenhelder, 1987). It is a fundamental human emotion recognized by behavioral and medical scientists as a basic condition of human existence. This emotion is often characterized as "something felt," an unpleasant affective state or condition (Freud, 1924). Fear and anxiety are similar in terms of their effects on the autonomic nervous system, i.e., sweating, rapid heart beat, and increased blood pressure. The difference between the two is in the ambiguity of the threat and the uncertainty of the danger to oneself present in anxiety (Miesenholder, 1987).

Transitory Anxiety

Research on anxiety as an emotional state has focused upon the general properties of transitory anxiety states and 
the conditions that evoke them (Spielberger, 1972). To define anxiety states in an individual, Krause (1961) reviewed the literature from psychology and psychiatry and concluded that transitory anxiety is typically inferred from 1) introspective verbal reports, 2) physiological signs, 3) "molar" behavior (i.e., body posture, restlessness and distortions of speech), 4) task performance, and 5) the response to stress. Basowitz et al. (1955) defined anxiety as "the conscious and reportable experience of intense dread and foreboding, conceptualized as internally derived and unrelated to external threat" (p.67). These introspective verbal reports, according to Krause, provide the most widely accepted basis for defining transitory anxiety in an individual.

Considerable research has been performed to develop the construct of anxiety. However, a single definition remains elusive because its manifestations differ among individuals, the nature of the activity performed, and the level of anxiety experienced (Sieber, O'Neil, \& Tobias, 1977). Izard (1972) identified anxiety as an unstable and variable combination of interacting fundamental emotions. It is unstable and variable because it is susceptible to change in relation to time, persons, and situations and because the fundamental emotions of the combination may vary in quality and intensity.

As a result of the complexity of anxiety, many different 
explanations or descriptions of the anxiety process exist in the literature. Mandler and watson (1966) proposed that anxiety occurs when an individual is interrupted in the course of executing a desired behavior sequence and has no alternative course of action available. The result of the interruption is an emotion of helplessness and disorganization which we call anxiety. Alpert and Haber (1960) also proposed that anxiety may facilitate or impair performance in evaluative situations depending on its nature.

Wine (1971) and Sarason (1972) felt that anxiety should be viewed primarily as an attentional phenomenon. The highly anxious person is one who attends to evaluative cues, to self-generated concern about ability to do well enough, and to feelings of physiological arousal. The person with low anxiety attends to the task at hand and to the operations required for dealing with it effectively. Spence and spence (1966) also evaluated individuals with low and high levels of anxiety but equated anxiety with drive level, discovering an interactive effect between anxiety and task difficulty on task performance.

Anxiety and Learning

Anxiety affects the ability to learn. It facilitates learning and performance of simple responses, and hinders that of complex responses (Goulet, 1968; Spence \& Spence, 1966). Anxiety can alter the perception of needs and distort thought and problem-solving processes, which, in turn, affect 
the learning process and productivity (Guzzeta, 1979). The Yerkes-Dodson law states that relationship between anxiety and learning is curvilinear with little learning occurring at very low or very high anxiety levels (in Levitt, 1967). Therefore, a middle range of anxiety is ideal (Griesbach, 1985).

Holmes and Masuda (1974) recommended calling any illness a stressful life event, especially an illness requiring a significant change in ongoing life patterns. Huckabay (1980) characterized the complex concepts (or "learning tasks") in diabetes education, such as calculating a diabetic diet, as requiring problem-solving skills. A high anxiety level can interfere with readiness and cause a drop in performance level. In fact, the impact of diabetes itself may interfere with learning (Fitzgerald, 1980). Gessner (1989) stated that previous educational encounters, interaction with the health care delivery system and knowledge of people with similar conditions affect the educational process.

In the case of Gestational Diabetes, this author has often observed clients arriving with the preconceived idea (derived from beliefs or experience) that they will automatically be placed on insulin. These preconceived ideas, and the anxiety that may accompany them, often compound the challenge of effective patient education. Anxiety affects other specific components of task performance such as memory, attention and incidental learning (sieber et 
al., 1977; wine, 1971). A highly anxious individual cannot remember information needed to formulate correct strategies, often making wrong choices. Anxious individuals tend to focus their attention on other things which makes incidental learning less likely to occur. Management of Ânxiety

Behaviors that result from anxiety may be expressed as helplessness, apathy, restlessness, irritability, or anger (Gilbert \& Harmon, 1986). These behaviors can become automatic and are often repeatedly used to relieve anxiety. Peplau (1957) states that each person has his or her own automatic manner for responding to anxiety.

Krohne and Laux (1982) feel that efficient problemsolving helps relieve psychological stress. The notion that psychological stress and social maladjustment can arise from ineffective problem-solving has been discussed by other researchers (D'Zurilla \& Goldfried, 1971; Goldfried \& Goldfried, 1975; Lukton, 1974; Mahoney, 1974). Krohne anà Laux (1982) proposed a series of specific cognitive operations and overt behaviors that are essential for efficient problem-solving. The cognitive operations include: 1) formulating and defining the problem as precisely as possible, 2) generating a list of alternative solutions including both general strategies and specific tactics, 3) assessing various consequences of each alternative and deciding which procedure should be used to solve the problem, 
and 4) implementing the chosen course of action and assessing its efficacy. By instructing the client in these general coping skills, he or she can apply them independently to deal with all situations in daily life. Mahoney (1974) emphasized problem-solving therapy as an educational process whereby the client learns how to function as his or her own "personal scientist." This approach seems particularly useful to the everyday problem-solving needed to manage GDM.

Caplan (1973) described pregnancy as a period of increased susceptibility to crisis. During pregnancy, physiological factors interact with psychological factors precipitating stress in all areas. Gilbert and Harmon (1986) proposed three conditions that must be met in order to cope and effectively adapt to the changing situations a high-risk pregnancy presents. First, information must be obtained. second, satisfactory maintenance of physiological and psychological functions must be present to foster the processing of information. Third, freedom to make decisions and to choose among options must exist. This is why it is so important for the health care professional dealing with the high-risk pregnancy to repeatedly provide information about the disease and the steps necessary for maintaining a healthy pregnancy. Information will facilitate a realistic appraisal of the events and prepare the woman for potential future events (Gilbert \& Harmon, 1986). 


\section{Self-Care}

The term "self-care" refers to the practices of individuals and families through which the forms of symptoms of illness are detected and treated, other diseases are prevented, and positive health behavior is generally promoted (DeFriese et al., 1989). The exchange model of self-care assumes that resources are limited and that exchange occurs because each side has something which is scarce and which the other side wants (Barofsky, 1978).

Several studies reported that, with good management, GDM pregnancy outcomes can be comparable to, if not better than, those of the general population (Gabbe et al., 1978; Goldberg et al., 1986; Hollander, 1988; Raz et al., 1988). self-care, in part, allows for the appropriate treatment to be provided. This treatment includes self blood sugar monitoring, diet, exercise, and, if necessary, insulin injections.

One study found that obtaining a knowledge of biood glucose fluctuations provided by self-monitoring of blood glucose (SMBG) allowed for appropriate changes in insulin and was often accompanied by an overall reduction in insulin requirements ( $\mathrm{Lam}, \mathrm{Ma}$, Chan, \& Yeung, 1984). However, in many cases of GDM, metabolic control can be maintained with SMBG and diet therapy alone (Hollander, 1988). In order to establish and maintain blood glucose control, the woman with GDM must be educated to all aspects of self-care. 


\section{Timing of Self-Care Instruction}

Anxiety related to a possible GDM diagnosis must be halted in the pregnant woman before it escalates and interferes with her mental health, ability to learn self-care and ultimate ability to comply with the prescribed regimen. Timely education is crucial. Research indicates that timing of self-care instruction plays an important role in increasing learning (Cohen, 1981; Griesbach, 1985). Guzzeta (1979) dealt with the relationship between stress and learning among post-myocardial infarction clients. Her results indicated that anxiety varies according to the time that the education occurred. Dyer and Chalfant (1978) studied diabetic client knowledge before and after teaching. They found the greatest knowledge gain occurred in those individuals who attended class after being hospitalized rather than during the hospitalization itself. Gessner (1989) observed that providing information close to the time it is needed and teaching when the patient is physiologically stable and free of pain are important to both relieving anxiety and increasing learning.

Based on this author's experience, the three-hour oral glucose tolerance test provides a unique and important opportunity for patient education. The pregnant woman has been alerted to a possible problem with her pregnancy but has had no formal instruction on GDM or self-care. She needs information at this stage to understand the effects this 
condition may have on her and to plan appropriate treatment. Educational intervention at this point might be highly effective and would allow the woman to keep her anxiety in check while she awaits a definitive diagnosis of Gestational Diabetes Mellitus. This study was designed to evaluate the effects of an instructional handout, designed to demystify GDM, on anxiety levels in the pregnant woman prior to her final diagnosis of Gestational Diabetes. 
CHAPTER 2

Design \& Methodology

Research Questions

1) Do women with a preliminary diagnosis of Gestational Diabetes Mellitus (GDM) experience high anxiety levels?

2) What do women with a preliminary GDM diagnosis know about Gestational Diabetes, its potential effect on their own health and its potential effect on their pregnancy?

3) Will reading an educational pamphlet on GDM during the three-hour oral glucose tolerance test decrease the patient's anxiety?

4) Will reading the educational pamphlet increase the patient's knowledge of GDM, its potential effect on her own health and its potential effect on her pregnancy? objectives

This study was designed to meet the following objectives:

1) To assess the anxiety and knowledge levels of pregnani women with a preliminary diagnosis of Gestational Diabetes Mellitus.

2) To assess the effectiveness of a new educational pamphlet in decreasing anxiety levels in the preliminarily diagnosed Gestational Diabetic.

3) To develop an educational tool that can standardize clinical practice, decrease anxiety, and increase knowledge in the individual being tested for Gestational 
Diabetes Mellitus.

4) To develop an educational tool that will contribute to increased compliance with the self-care regimen prescribed for the Gestational Diabetic patient.

5) To decrease the potential complications of Gestational Diabetes to the mother and child.

\section{Sample}

This exploratory study utilized a convenience sample of 25 women who had received a preliminary diagnosis of Gestational Diabetes between October, 1989 and December, 1989 at the Sunnyvale Medical Clinic (SVMC), Sunnyvale, California. Site approval was obtained from SVMC on October 1, 1989 (Appendix C). Study approval was obtained from the Human Subjects Committee of the San Jose State University Institutional Review Board on October 9, 1989 (Appendix D). The standard practice of the SVMC is to perform a routine one-hour oral glucose tolerance test between the 24 th and 28th week of pregnancy. Women "failing" that test (i.e., blood sugar level greater than $140 \mathrm{mg} / \mathrm{dl}$ ) are given a "preliminary" GDM diagnosis. Test results and the preliminary diagnosis are delivered over the phone by either the nurse or physician. At that point, the woman is scheduled to come in to the clinic for the definitive threehour oral glucose tolerance test (OGTT). The OGTT involves a fasting blood sugar test followed by ingestion of a 100 gram glucose load and then three blood sugar samples taken at one 
hour intervals following the drink. If the second test results confirm the GDM diagnosis, the patient is instructed to make a future appointment with the Diabetes Nurse Educator. It is not until this appointment that the pregnant woman receives any formal patient education about GDM. Sample selection began with the first client appearing for the three-hour oral glucose tolerance test during the study period and proceeded until 25 subjects had completed both pre- and post-tests. Patients were approached by the investigator, a staff diabetes educator at the clinic, as they waited in the laboratory waiting room. Potential subjects were excluded if they had been diagnosed with GDM in a previous pregnancy or could not speak English. Those who qualified for the study were invited to participate and given the informed consent materials (Appendix E). When the informed consent form was signed by both patient and investigator, the patient was given the pre-test instrument.

Instrument

To measure anxiety and knowledge levels, a questionnaire was derived from two sources. The first was the Differential Emotion Scale and Anxiety Scale (DES \& A) (Appendix A), developed by Carroll Izard, 1966. This questionnaire combines a list of fundamental emotions with a set of adjective scales that enables subjects to indicate the degree to which each of the fundamental emotions is present in any given experience (Izard, 1972). The scale includes 51 
emotion adjectives that the subject rates on a 5 point likert scale, ranging from very slightly, slightly, moderately, strongly to very strongly.

The aim of the original construction of the Differential Emotion Scale (DES) was to develop relatively independent scales or factors responding to each fundamental emotion (Izard, 1972). The original design encompassed 72 emotion adjectives, rated on a 5-point scale. This scale was administered to two groups, entering freshmen and black college students, who were asked to evaluate certain scenarios. Validity and reliability of the DES instrument were tested and verified through these studies (Izard, 1972). The DES scale was then combined with a standard anxiety scale. The anxiety scale Izard used was the spielberger Gorusch - Lushene stait trait anxiety inventory (STAI) (Spielberger, 1972). This scale was chosen because it correlated well with other well accepted anxiety measures (Izara, 1972). Now called the combined DES \& A scale, the expanded instrument represents ten emotion concepts, one nonemotion concept and an anxiety scale, and is commonly used to measure anxiety (Izard, 1972).

The other half of the research instrument was an original questionnaire testing for health beliefs specifically related to Gestational Diabetes (Appendix B). Questions were adapted from a health belief scale developed by Given et al. in 1983. Given's scale was specifically 
designed to measure diabetic patients' beliefs about disease and therapy. For this research, a set of 22 questions related to beliefs about Gestational Diabetes was developed from the Given's scale. Questions were designed to conform with the key dimensions of the health belief model (HBM). Becker and Janz (1985), using the health belief model, placed questionnaire items from the Given's scale into four different categories (Appendix F). Each of these categories represents one dimension of the HBM, i.e., perceived severity, perceived susceptibility, perceived benefits and perceived barriers. An additional category was added to explain individual respondent's perceived self-efficacy (Rosenstock, 1985). For this study, questions were included to probe the patient's understanding of Gestational Diabetes, sense of trust and communication with her physician. These latter questions were based on the author's experiences of the most common concerns of preliminarily diagnosed Gestational Diabetics in her work at the SVMC.

\section{Procedures}

Data were collected through a written pre- and posttest questionnaire. The pre-test was used to measure the patient's initial anxiety, her knowledge of GDM and her confidence in her ability to manage this disorder. Respondents were given an instructional handout on GDM (Appendix G) after they turned in a completed pre-test. The post-test (Appendix H), consisting of identical questions in 
different order, was used to measure attitude and knowledge change after reading the instructional pamphlet. The entire sequence (pre-test, pamphlet, post-test) took approximately 45-60 minutes to complete. All three steps were completed while the participant waited in the clinic laboratory for the three hours required for the oral glucose tolerance test (OGTT) .

The size of the waiting room and seating arrangements allowed for ample privacy and comfort. Subjects were selected from the population of women checking into the laboratory for the three-hour OGTT. The researcher, a diabetes nurse educator normally present in the waiting area, approached each potential participant, explained the study and invited each eligible patient to participate. Interested patients were given the informed consent materials. When the informed consent was signed, the researcher assigned a record number to the participant and handed her the pre-test from a pre-numbered packet. This record number allowed for anonymity to be maintained throughout the study. Participants worked at their own pace from any place in the lab waiting room. Study participants returned the completed pre-test to the receptionist who then gave them the instructional pamphlet. They were asked to pick up the pre-numbered posttest after reading the pamphlet and to return it, when completed, to the receptionist. The researcher trained and supervised the receptionist and was available at all times 
for questions.

Following the completion of the data collection, participants' charts at the Sunnyvale Medical Clinic were reviewed to obtain information on age, marital status, and number of previous pregnancies in order to construct a profile of the consenting group. Because record numbers could not be matched with signed consents, the chart review could only yield a profile of the group as a whole rather than individual participants.

The two parts of the questionnaire, anxiety and beliefs about GDM, were analyzed separately although in a similar manner. Pre-test data were examined to provide a baseline assessment of participants' anxiety and pre-exisiting beliefs about Gestational Diabetes. Questionnaire items were organized into theoretically based clusters. Within each cluster, the group mean and standard deviation were calculated for each question. This enabled intra- and intercluster mean and variance comparisons. The correlated twotailed $\underline{t}$-test was used to determine the significance of any changes between pre- and post-test responses for individual questions and for theoretical clusters. 
CHAPTER 3

Results

Sample selection

Sample selection began in october, 1989 and concluded in January, 1990. A total of 45 individuals participated in some part of this study. Twenty of the 45 participants were excluded at various points in the research process. Eight potential respondents were disqualified prior to the pretest: five were eliminated because of a language barrier and three for prior knowledge of Gestational Diabetes. The responses of twelve participants were eliminated because they did not follow the study protocol. Specific reasons for elimination at this point included: 1) leaving out a whole side of the questionnaire $(n=5), 2)$ leaving incomplete responses $(n=4), 3)$ leaving an entire column incomplete on the post-test $(n=2)$, and 4$)$ answering the questionnaire without reading the handout $(n=1)$. After eliminating those 20 participants, a final sample of 25 emerged.

In an attempt to understand more about the participants, medical records were evaluated for information relevant to the study. Consent forms could not be matched to completed questionnaires, so it was impossible to identify the subset of 25 who had actually completed the study. However, of the 37 who began the study, 32 charts were available for review. From these data, a profile of the consenting group was constructed. This group ranged in age from 17 to 39 years 
old with an average age of 29. The majority $(n=24)$ were employed. Ethnicity, as noted on the patient's chart, was distributed as follows: Caucasian (50\%), Asian (22\%), Hispanic (12.5\%), Indian (9\%) and unknown (6\%). Eleven participants were in their first pregnancy, 16 in their second pregnancy, three were in their third, one in her fifth and one participant was pregnant for the seventh time. There was a combined total of 17 previous abortions (therapeutic or otherwise) in this group. Only one of the 32 participants was unmarried.

Anxiety and beliefs about Gestational Diabetes Mellitus made up the two parts of the questionnaire that was administered to participants. Each part was analyzed separately, but in a similar manner. Pre-test data allowed for a baseline assessment of the participants' anxiety and beliefs about GDM. Questionnaire items were organized into either clusters or factors based on the theoretical models from which they were derived. The group mean and standard deviation were calculated for each item followed by calculation of cluster means and variance. This allowed for intra- and inter-cluster mean and variance comparisons to be made. A correlated two-tailed t-test was used to assess the significance of the change in participants' scores on each of the items, and the overall groupings, between the pre- and post-test. 


\section{Pre-Test Anxiety}

Following the model from which the DES \& A measurement tool was derived, particular questionnaire items were combined into factors which represent the nine theoretical dimensions of anxiety (Izard, 1972). Tables I through 9 describe participant response in reference to these theoretical dimensions of interest, enjoyment, surprise, distress, anger, shyness, fear, fatigue and calmness.

Three items (alert, attentive and concentrating) were analyzed together to indicate participants' interest levels. 
Table 1

Pre-Test DES \& A Means and Standard Deviations for

Questionnaire Items Regarding Interest

Item $\underline{M} \quad \underline{\text { SD }}$

\begin{tabular}{lcc}
\hline Alert & 2.92 & .93 \\
Attentive & 3.60 & .80 \\
Concentrating & 2.56 & .89 \\
\hline Overall Interest & 3.03 & .87 \\
\hline
\end{tabular}

Note. Respondents were asked to indicate the degree to which each word "describes your feelings right now". Response range: $5=$ very strongly; $1=$ very slightly or not at all. $\underline{\mathrm{N}}=25$.

The overall mean score for participants' interest was 3.03 with a standard deviation of .87 (Table 1). The mean scores for two of these interest adjectives in particular, attentive (3.60) and alert (2.92), suggest that respondents identified fairly strongly with these emotions. The standard deviation of each of the three items in this anxiety factor was less than one rating point. 
Table 2

Pre-Test DES \& A Means and Standard Deviations for

Questionnaire Items Regarding Enjoyment

\begin{tabular}{lcc} 
Item & $\underline{M}$ & $\underline{S D}$ \\
\hline Happy & 2.08 & 1.02 \\
Pleasant & 2.60 & 1.17 \\
Joyful & 1.60 & .85 \\
Content & 2.44 & 1.13 \\
Delighted & 1.56 & .80 \\
Secure & 2.68 & 1.05 \\
Confident & 2.52 & 1.02 \\
Relaxed & 2.68 & .97 \\
At Ease & 2.48 & 1.02 \\
Rested & 2.44 & 1.10 \\
Comfortable & 2.72 & .96 \\
\hline Overall Enjoyment & 2.34 & 1.01 \\
\hline
\end{tabular}

Note. Respondents were asked to indicate the degree to which each word "describes your feelings right now". Response range: $5=$ very strongly; $1=$ very slightly or not at all. $\underline{N}=25$.

Table 2 is comprised of 11 questionnaire items that indicate the emotion of enjoyment posed by Izard (1972) as the "negative of anxiety." In comparison to the interest factor shown in Table 1 (overall $\underline{M}=3.03, \underline{S D}=.87$ ), this set of 
adjectives had a lower overall mean score (2.34) with an overall higher degree of variability ( $\underline{S D}=1.01)$.

The highest individual means of the enjoyment factor corresponded to the adjectives comfortable (2.72), relaxed (2.68), and secure (2.68). Two of the three (relaxed and comfortable) had some of the lowest variability of the responses in this group ( $\underline{S D}=.97$ and .96 , respectively). In contrast, respondents showed little identification with the adjectives delighted $(\underline{M}=1.56)$ and joyful $(\underline{M}=1.60)$. Their lower degree of variability $(\underline{S D}=.80$ and .85$)$ indicates that respondents agreed in their lack of identification with these adjectives. The mean responses to the adjectives confident and at ease were located near the central response value $(2.52$ and 2.48) with an identical standard deviation (1.02). 
Table 3

Pre-Test DES \& A Means and Standard Deviations for

Questionnaire Items Regarding Surprise

Item

$\underline{\mathbf{M}}$

$\underline{\text { SD }}$

\begin{tabular}{lcc} 
Amazed & 2.00 & 1.26 \\
Astonished & 2.16 & 1.32 \\
Surprised & 2.56 & 1.58 \\
\hline Overall surprise & 2.24 & 1.39 \\
\hline Note. Respondents were asked to indicate the degree to \\
each word "describes your feelings right now". \\
range: $5=$ very strongly; $1=$ very slightly or not at all. \\
N=25.
\end{tabular}

Table 3 reflects the responses to the three questionnaire items that express the emotion of surprise. In comparison to the interest and enjoyment factors, the combined set of adjectives has the lowest overall mean score but the highest variability $(\underline{M}=2.24, \underline{S D}=1.39)$. Only the adjective surprised had a mean value above the center $(\underline{H}=2.56)$ but the extremely high degree of variation $(\underline{S D}=1.58)$ suggests that respondents disagreed in their degree of identification with this adjective. 
Table 4

Pre-Test DES \& A Means and Standard Deviations for

Questionnaire Items Regarding Distress

Item

프

SD

Regretful

1.60

1.02

Blameworthy

1.36

.69

Guilty

1.56

1.02

Repentant

2.16

.92

Downhearted

2.16

1.05

Upset

1.92

1.16

sad

1.56

.94

Discouraged

2.04

.92

Overall Distress

1.80

.97

Note. Respondents were asked to indicate the degree to which each word "describes your feelings right now". Response range: $5=$ very strongly; 1 - very slightly or not at all. $\underline{N}=25$.

Eight questionnaire items make up the combination of emotions that represent distress, described by Izard as including the emotions of guilt and anxiety (Table 4). The distress adjectives had lower mean scores (overall $\underline{M}=1.80$ ) than the other factor groups with a relatively low degree of variability (overall $\underline{\mathrm{SD}}=.97$ ).

The highest mean scores of the individual distress items 
corresponded to the adjectives repentant (2.16), downhearted (2.16) and discouraged (2.04). However, the means of all of the adjectives were well below the central point (2.50). Some of the lowest variability of the responses in this group corresponded to the adjectives repentant and discouraged $(\underline{S D}=.92$ for both), suggesting that there was little disagreement among respondents. The lowest mean to date corresponded with the adjective blameworthy $(\underline{M}=1.36)$. The corresponding low degree of variability $(\underline{S D}=.69)$ indicates that respondents agreed in their overall rejection of this emotion. 
Table 5

Pre-Test DES \& A Means and Standard Deviations for

Questionnaire Items Regarding Anger

Item $\underline{M} \quad \underline{S D}$

Mad

1.64

1.02

Angry

1.48

.81

Disgusted

1.44

.70

Enraged

1.44

.70

Scornful

1.56

.94

Contemptuous

1.76

.91

Feeling of Revulsion

1.48

.75

Disdainful

1.48

.70

Feeling of Distaste

1.80

.94

Overall Anger

1.56

.83

Note. Respondents were asked to indicate the degree to which each word "describes your feelings right now". Response range: $5=$ very strongly; $1=$ very slightly or not at all. $\underline{N}=25$.

Table 5 displays responses to 9 questionnaire items that Izard combined to represent the emotions of anger, disgust, and contempt. This factor had the lowest overall mean (1.56) and variability $(\underline{S D}=.83)$ of any of the previous four factors. The means of all 9 adjectives cluster in the range between 1.44 and 1.80 . These data suggest that there was a lack of 
identification with the anger adjectives. The generally lower standard deviations further indicate that respondents were in agreement with this lack of identification. It is interesting to note that the three anger adjectives with the highest means (feeling of distaste, 1.80; contemptuous, 1.76; and mad, 1.64) also had the highest standard deviations $(.94, .91$ and 1.02 , respectively). 
Table 6

Pre-Test DES \& A Means and Standard Deviations for

Questionnaire Items Regarding Shyness

\begin{tabular}{lcc} 
Item & $\underline{M}$ & $\underline{\text { SD }}$ \\
\hline Shy & 1.60 & .85 \\
Bashful & 1.60 & .85 \\
Sheepish & 1.40 & .69 \\
\hline Overall Shyness & 1.53 & .80 \\
\hline
\end{tabular}

Note. Respondents were asked to indicate the degree to which each word "describes your feelings right now". Response range: $5=$ very strongly; $1=$ very slightly or not at all. $\underline{N}=25$.

Table 6 includes three items that represent the emotion of shyness. Similar to the anger factor, the shyness factor also had the lowest mean scores and standard deviations in comparison to the other factors. It appears that respondents showed little identification with any of the three adjectives (overall $\underline{M}=1.53$; overall $\underline{\mathrm{SD}}=.80$ ). The adjective sheepish had the lowest mean (1.40) and degree of variability ( $\underline{S D}=.69)$ which indicates that respondents strongly agreed in their lack of identification with this adjective in particular. 
Table 7

Pre-Test DES \& A Means and standard Deviations for

Questionnaire Items Regarding Fear

Item

$\underline{\mathbf{M}}$

SD

\begin{tabular}{lcc} 
Nervous & 2.64 & 1.02 \\
Tense & 2.04 & 1.04 \\
Jittery & 2.08 & .98 \\
Fearful & 2.24 & 1.07 \\
Afraid & 2.56 & 1.24 \\
Worried & 2.88 & 1.11 \\
Scared & 2.40 & 1.17 \\
Overexcited \& Rattled & 1.64 & .79 \\
Anxious & 2.48 & 1.10 \\
High Strung & 2.00 & 1.02 \\
\hline Overall Fear & 2.30 & 1.05
\end{tabular}

Note. Respondents were asked to indicate the degree to which each word "describes your feelings right now". Response range: $5=$ very strongly; $1=$ very slightly or not at all. $\underline{N}=25$.

Ten questionnaire items were combined to form the factor group which Izard uses to represent the emotions of fear and anxiety (Table 7). Although the concept is very different, the overall response to this set of adjectives $(\underline{M}=2.30$; $\underline{S D}=1.05$ ) was very similar to that of the enjoyment factor 
$(\underline{M}=2.34 ; \underline{S D}=1.01)$. Both factors had means in the mid-range with a relatively higher degree of variability. The highest mean scores of the fear factor group corresponded to the adjectives worried (2.88), nervous (2.64) and afraid (2.56). This set of adjectives also showed some of the highest variability of the responses in this group (1.11, 1.02 and 1.24 , respectively).

In contrast, respondents showed less identification with the adjectives over-excited and rattled $(\underline{M}=1.64)$, high strung $(\underline{M}=2.00)$, tense $(\underline{M}=2.04)$ and jittery $(\underline{M}=2.08)$. Considerably lower variability appeared in one of the four items, overexcited/rattled $(\underline{S D}=.79)$, which indicates that respondents agreed in their lack of identification with this adjective. There was less agreement in the other three responses, high strung $(\underline{S D}=1.02)$, tense $(\underline{S D}=1.04)$ and jittery $(\underline{S D}=1.07)$. These standard deviations are similar to the variability of the rest of the items in this factor group. 
Table 8

Pre-Test DES \& A Means and standard Deviations for Questionnaire Items Regarding Fatique

\begin{tabular}{lcc} 
Item & $\underline{M}$ & $\underline{\text { SD }}$ \\
\hline Sleepy & 2.48 & 1.24 \\
Fatigued & 2.60 & 1.17 \\
Sluggish & 2.08 & .93 \\
\hline Overall Fatigue & 2.39 & 1.11 \\
\hline
\end{tabular}

Note. Respondents were asked to indicate the degree to which each word "describes your feelings right now". Response range: $5=$ very strongly; $1=$ very slightly or not at all. $\underline{N}=25$.

Table 8 reflects the combination of questionnaire items that describe the emotion of fatigue. This factor showed the third highest overall mean (2.39). The highest mean score, represented by the adjective fatigued (2.60), suggests that respondents, as a group, identified with this emotion, but the wide standard deviation (1.17) indicates considerable disagreement within the group itself. The mean response of the adjective sleepy was located near the central value (2.48) with a wider degree of variation $(\underline{S D}=1.24)$. In contrast, respondents showed more agreement but less identification with the adjective sluggish ( $\underline{M}=2.08, \underline{S D}=.93)$. 
Table 9

Pre-Test DES \& A Means and Standard Deviations for Questionnaire Items Regarding calmness

Item $\underline{M} \underline{\text { SD }}$

$\begin{array}{lll}\text { Calm } & 3.16 & .78\end{array}$

Note. Respondents were asked to indicate the degree to which each word "describes your feelings right now". Response range: $5=$ very strongly; $1=$ very slightly or not at all. $\underline{N}=25$.

The DES \& A model separates calm from the other emotion adjectives (Table 9). This item not only received one of the highest $\underline{M}$ values (3.16) for the anxiety scale but it also showed a very low degree of variability $(\underline{S D}=.78)$ compared to the rest of the factors (Tables $1-8$ ). These values suggest that the study's participants identified strongly with this adjective and that there was agreement on this response. 
Table 10

Pre-Test DES \& A Overall Factor Means and Standard Deviations

\begin{tabular}{lcc} 
Factor & $\underline{\mathrm{M}}$ & $\underline{\mathrm{SD}}$ \\
\hline Interest & 3.03 & .87 \\
Enjoyment & 2.34 & 1.01 \\
Surprise & 2.24 & 1.39 \\
Distress & 1.80 & .97 \\
Anger & 1.56 & .83 \\
Shyness & 1.53 & .80 \\
Fear & 2.30 & 1.05 \\
Fatigue & 2.39 & 1.11 \\
Calm & 3.16 & .78 \\
\hline
\end{tabular}

Note. Figures are average means and standard deviations for factor groups.

In summary, responses to the pre-test DES \& A scale indicated fairly neutral emotional responses with a wide range of variability. Table 10 displays the overall mean and standard deviation for each emotion factor. The factors with the highest overall means, indicating the strongest degree of identification, were calm (3.16) and interest (3.03). These two factors also showed some of the lowest variability $(\underline{S D}=.78$ and .87 , respectively) of the 9 factors in the scale, indicating not only the strongest degree of identification but also strong agreement within the group. 
Respondents exhibited less overall identification with shyness $(\underline{M}=1.53)$, anger $(\underline{M}=1.56)$ and distress $(\underline{M}=1.80)$. Their low overall variability $(\underline{S D}=.80, .83$, and .97) suggests that respondents agreed in their lack of identification or rejection of these feelings. And finally, the overall mean values for the factors of enjoyment (2.35), surprise (2.24), fear (2.30) and fatigue (2.39) were located slightly below the central value but have elevated standard deviations $(1.01,1.39,1.05$, and 1.11) suggesting that those mid-range means may obscure at least some extreme scores and a wide range of individual item variability.

\section{Pre-Test Health Beliefs}

Tables 11 - 15 represent the responses to the pretest questions regarding participants' GDM-related health beliefs. Following the most recent adaptions of the health belief model, clusters were created in order to analyze its key components separately (Rosenstock, 1985). The five clusters from the expanded health belief model are: i) perceived severity (Table 11), 2) perceived susceptibility (Table 12), 3) perceived benefits (Table 13), 4) perceived barriers (Table 14), and 5) perceived efficacy (Table 15). Two additional clusters were created to address beliefs about trust and perceptions about the communication between respondent and health care provider (Tables 16 and 17). 
Table 11

Mean and Standard Deviation of Pre-Test Questionnaire Items Regarding Perceived Severity

Item $\underline{\mathbf{M}}$

$\underline{\text { SD }}$

My diabetes will affect the health of my baby.

$$
3.00
$$

My diabetes will have a negative effect on my future health.

$$
2.48
$$$$
.94
$$

My diabetes will cause me to be sick a lot.

$$
2.24
$$

Overall Perceived Severity

2.57

.99

Note. Respondents were asked to indicate the degree to which each statement "describes your feelings about Gestational Diabetes". Response range: 5= strongly agree; $1=$ strongly disagree. $\underline{N}=25$.

Three questionnaire items were combined to form the cluster representing respondents' beliefs about the severity of GDM (Table 11). The first item in this cluster asked the respondent about the effect on the baby. This question received the highest mean response (3.00) and had the highest degree of variability $(\underline{S D}=1.23)$. This suggests that respondents as a group agreed with this statement, but that there was some degree of disagreement within the group. The second and third questions in this cluster asked participants about 
their own future health. Respondents appear to have perceived the severity of GDM as less for themselves than for the baby ( $\underline{M}=2.48,2.24$ respectively) with less variation in responses $(\underline{S D}=.94$ and .81$)$. 
Table 12

Mean and Standard Deviation of Pre-Test Questionnaire Items Regarding Perceived susceptibility

Item

$\underline{\mathbf{M}}$

SD

I will have diabetes sor the rest of my life.

$$
1.84 \quad .78
$$

Gestational Diabetes can be a serious disease if you don't control it. $4.12 \quad .71$

My diabetes will be worse if I do nothing about it. 4.40 .85

I feel more nervous about my pregnancy now then I did before my appointment. 3.28 1.22

I am anxious about this pregnancy.

$$
3.48
$$

I am nervous about the consequences of this pregnancy.

$$
2.92
$$

Overall Perceived Susceptibility

$$
3.34
$$

.98

Note. Respondents were asked to indicate the degree to which each statement "describes your feelings about Gestational Diabetes". Response range: 5= strongly agree; $1=$ strongly disagree. $\underline{N}=25$.

This cluster is a combination of six questionnaire items that probe respondents' beliefs about their 
susceptibility to GDM (Table 12). Responses within this cluster displayed a wider range of means and generally lower variation than those of perceived severity. The highest mean scores of the perceived susceptibility cluster corresponded to Item \#2, which asked the respondent about the severity of $G D M(M=4.12)$, and \#3, which asked about personal control $(\underline{M}=4.40)$. These two statements had some of the lowest variability of the responses in this group ( $\underline{S D}=.71$ and .85 , respectively) suggesting that respondents agree in their strong belief that GDM can be serious and will be worse unless they do something about it.

In contrast, respondents showed little identification with the first statement in this cluster which questioned the respondent about the longevity of diabetes $(M=1.84)$. Its lower degree of variability $(\underline{S D}=.78)$ suggests that respondents agreed in their rejection of this statement. Responses to the last three items, which asked respondents about anxiety specific to their current pregnancy, had high mean scores $(3.28,3.48,2.92$, respectively) but their high degree of variability $(\underline{S D}=1.22,1.17,1.13)$ in contrast to the other items in this cluster suggests that there was disagreement among respondents. 
Table 13

Mean and Standard Deviation of Pre-Test Questionnaire Items Regarding Perceived Benefits

Item

$\underline{S D}$

I know that my physician will assist me in making changes to $\begin{array}{lll}\text { manage my diabetes. } & 3.88 & .77\end{array}$

I trust my physician to help me maintain a healthy pregnancy. $4.16 \quad .61$

I feel that my physician will assist me to have a healthy baby.

$$
4.04 \quad .72
$$

I can control the seriousness of my condition.

$$
3.92 \quad .56
$$

I am confident about my ability to maintain a healthy $\begin{array}{lll}\text { pregnancy. } & 3.72 & .83\end{array}$

My doctor helped me understand my diabetes.

2.72 .92

Overall Perceived Benefits

3.74 .74

Note. Respondents were asked to indicate the degree to which each statement "describes your feelings about Gestational Diabetes". Response range: 5= strongly agree; $1=$ strongly disagree. $\underline{\mathrm{N}}=25$.

Six questionnaire items were combined to form the cluster that identifies the respondents' beliefs about the benefits of treating GDM (Table 13). In comparison to the 
perceived susceptibility (Table 10) and perceived severity clusters (Table 12), this set of health belief statements received very high mean values with an extremely low degree of variability. The highest mean scores corresponded to the first five responses which ask respondents about physician assistance and personal control ( $\underline{M}=3.72$ to 4.16$)$. The lower degree of variability $(\underline{S D}=.56$ to .83$)$ suggests that respondents agreed in their identification with these statements. Respondents appeared to have perceived important benefits provided to them by the health care profession. In contrast, the last item, which asked the respondent if the doctor helped her understand her diabetes, suggests that respondenics had notably less agreement with this statement $(\underline{M}=2.72, \underline{S D}=.92)$. 
Table 14

Mean and Standard Deviation of Pre-Test Questionnaire Items Regarding Perceived Barriers

Item $\underline{\mathbf{M}}$

$\underline{\text { SD }}$

It will be difficult to make changes in my lifestyle while I'm pregnant. $\quad 2.56 \quad 1.13$

I am uncertain of my ability to make all of the changes necessary to manage my diabetes.

$$
2.44 \quad .98
$$

It seems like too many changes will be necessary to manage my diabetes. 2.52 .64

I don't understand what my physician tells me.

$$
2.24
$$

I am confused by what my doctor tells me.

$$
2.20
$$

.89

Overall Perceived Barriers 2.39 .98

Note. Respondents were asked to indicate the degree to which each statement "describes your feelings about Gestational Diabetes". Response range: 5= slightly agree; $1=$ slightly disagree. $\underline{N}=25$.

Table 14 displays the combination of five questionnaire items which identify the respondents' beliefs regarding barriers to the successful management of GDM. This perceived barriers cluster had the lowest mean scores and highest 
degree of variability compared to the other cluster groups (Table 11-13). The highest mean of the cluster was represented by Item \#1, which asks about the difficulty of making changes $(\underline{M}=2.56)$. The data suggest that there was some disagreement with this response value ( $\underline{S D}=1.13)$. In contrast, respondents showed less identification with Item \#5, which asks respondents about confusion in communication with their physician $(\underline{M}=2.20)$ but there appears to be more agreement with this response among respondents $(\underline{S D}=.89)$. Item \#4, which asks respondents about how well they understand their physicians' advice received a similar response $(\underline{M}=2.24)$, but had the highest degree of variability of all of the statements in this cluster $(\underline{S D}=1.24)$. Finally, the mean response to Item \#3, which asks the respondent about her belief regarding the many changes required for self-care management $(\underline{M}=2.52)$, was located near the central response value and has the lowest standard deviation of all other items in this group $(\underline{S D}=.64)$. 
Table 15

Mean and standard Deviation of Pre-Test Questionnaire Items Regarding Perceived Efficacy

Item

$\underline{\mathbf{M}}$

$\underline{S D}$

I believe I can control my diabetes.

4.20

.63

Making changes is something that one must do no matter

how hard it is.

4.20

.57

Overall Perceived Efficacy

4.20

.60

Note. Respondents were asked to indicate the degree to which each statement "describes your feelings about Gestational Diabetes". Response range: $5=$ slightly agree; $1=$ slightly disagree. $\underline{N}=25$.

Two questionnaire items were combined to form the cluster representing respondents' beliefs about their own ability to follow the required regimen of care for individuals with GDM (Table 15). This cluster had the highest $\mathrm{M}$ values (4.20 for both statements) and the lowest variability ( $\underline{S D}=.63$ and .57 , respectively) of any items in the other health belief clusters (Tables 11-14). These scores suggest that respondents as a group felt strongly about the importance of making changes and, perhaps more importantly, had a high degree of confidence in their own abilities to make the changes. The lower degree of variability indicates that, 
within the group, they agreed in their strong identification with these two statements.

From the original cluster grouping for Table 13

(perceived benefits) and Table 14 (perceived barriers), six items were selected to form two new categories: perceived trust and health care provider communication. 
Table 16

Mean and Standard Deviation of Pre-Test Questionnaire Items Regarding Perceived Trust

Item

$\underline{\mathbf{M}}$

$\underline{\text { SD }}$

I know that my physician will assist me in making changes to manage my diabetes. $3.88 \quad 077$

I trust my physician to help me maintain a healthy pregnancy. $\begin{array}{ll}4.16 & .61\end{array}$

I feel that my physician will assist me to have a healthy baby. 4.04 .72

Overall Trust

4.03 .70

Note. Respondents were asked to indicate the degree to which each statement "describes your feelings about Gestational Diabetes". Response range: 5= strongly agree; $1=$ strongly disagree. $\quad \underline{N}=25$.

The items in Table 16 asked respondents about the trust they have in their physicians. Some of the highest mean responses for all cluster groups were represented by items in the perceived trust cluster (overall $\underline{M}=4.03$ ). The data suggest that respondents strongly identified with each of the trust statements. The low degree of variability (overall $\underline{S D}=.70$ ) indicates that respondents agreed in their strong trust in their physicians. 
Table 17

Mean and Standard Deviation of Pre-Test Questionnaire Items

Regarding Health Care Provider Communication

Item

$\underline{\mathbf{M}}$

$\underline{S D}$

My doctor helped me understand my diabetes.

$$
2.72
$$

I don't understand what my physician tells me.

$$
2.24
$$

I am confused by what my doctor tells me.

$$
2.20
$$

Overall Health Care Provider Communication

$$
2.39
$$

1.02

Note. Respondents were asked to indicate the degree to which each statement "describes your feelings about Gestational Diabetes". Response range: 5= strongly agree; $1=$ strongly disagree. $\underline{N}=25$.

Table 17 represents health care provider communication, but unlike the trust cluster (Table 16), had lower means with a higher degree of variability. The highest mean score of the health care provider communication cluster corresponded to Item \#I, which asks respondents whether their physician helped them understand GDM $(\underline{M}=2.72)$. This statement had a relatively low degree of variability in comparison to the rest of the group $(\underline{S D}=.92)$. Respondents showed little 
identification with Item \#2, which asks respondents about their understanding of their physicians $(\underline{M}=2.24)$. This item had the highest variability $(\underline{S D}=1.24)$ of any statement in the six health belief cluster groups. These values indicate that respondents feel that they understand their physicians, but that they also feel that their physicians are not helping them understand their diabetes. 
Table 18

Pre-Test Health Belief Overall Means and Standard Deviations Item $\underline{M}$

$\underline{\text { SD }}$

Perceived Severity 2.57 .99

Perceived Susceptibility

3.34

.98

Perceived Benefits

3.74

.74

Perceived Barriers

2.39

.98

Perceived Efficacy

4.20

.60

Perceived Trust

4.03

.70

Perceived Health Care Provider Communication

2.39

1.02

Note. Figures are average means and standard deviations for questionnaire items.

In summary, responses to the pre-test health belief questions indicate that respondents identified more strongly with the health belief statements than with the adjectives in the DES \& A scale. The DES \& A scale had relatively lower mean values with a much wider range of variability, while the pattern of responses to the health belief scale was reversed with higher mean scores and a lower range of variability (Table 18). 
Anxiety: Differences Between Pre- and Post-Test Scores

A correlated t-test was used to assess the significance of the change in participants' anxiety scores between the pre- and post-test. Differences between pre- and post-test scores were determined and a correlated $t$-test was performed. 
Table 19

Pre \& Post-Test Differences and T-Scores for ouestionnaire Items Regarding Interest

Item

$\begin{array}{cc}\text { Pre-test } & \text { Post-test Change } \\ \underline{M}(\underline{S D}) & \underline{M}(\underline{S D})\end{array}$

\begin{tabular}{lcccc}
\hline Alert & $2.92(.93)$ & $3.04(.77)$ & .12 & 1.25 \\
Attentive & $3.60(.80)$ & $3.20(.94)$ & -.40 & $3.54 * *$ \\
Concentrating & $2.56(.85)$ & $2.64(.84)$ & .08 & 1.49 \\
\hline Overall Interest & $3.03(.87)$ & $2.96(.85)$ & -.07 & \\
\hline
\end{tabular}

Note. Response range: $5=$ very strongly; $1=$ very slightly or not at all. $\underline{\mathrm{df}}=24$.

$* \underline{p}<.05 . * * \underline{p}<.01$.

Table 19 displays the three questionnaire adjective responses that were combined to form the interest cluster. Both overall factor and individual item t-test scores suggest that there was not much significant change in interest from the pre- to the post-test. The adjective attentive was the only one in which a statistically significant change occurred (-.40, $\mathrm{p}<.01)$ indicating that participants' attentiveness decreased over the pre- and post-test time period. 
Table 20

Pre \& Post-Test Differences and T-Scores for Questionnaire

Item Regarding Enjoyment

\begin{tabular}{lllll} 
Item & $\begin{array}{c}\text { Pre-test } \\
\underline{M}(\underline{S D})\end{array}$ & $\begin{array}{c}\text { Post-test } \\
\underline{M}(\underline{S D})\end{array}$ & Change & $\underline{t}$ \\
\hline Happy & $2.08(1.02)$ & $1.92(.94)$ & -.16 & 1.02 \\
Pleasant & $1.56(1.17)$ & $2.00(.94)$ & .44 & $3.69 * *$ \\
Joyful & $1.60(.85)$ & $1.80(1.06)$ & .20 & 1.83 \\
Content & $2.44(1.13)$ & $2.56(.90)$ & .12 & $2.54 *$ \\
Delighted & $1.56(.80)$ & $1.64(.84)$ & .08 & .60 \\
Secure & $2.68(1.05)$ & $2.64(1.05)$ & -.04 & .02 \\
Confident & $2.52(1.02)$ & $2.76(.81)$ & .24 & $7.62 * *$ \\
Relaxed & $2.68(.97)$ & $2.72(.87)$ & .04 & $4.28 * *$ \\
At ease & $2.48(1.02)$ & $2.48(.94)$ & 0 & \\
Rested & $2.44(1.10)$ & $2.36(1.02)$ & -.08 & .60 \\
Comfortable & $2.72(.96)$ & $2.56(.90)$ & -.18 & .86 \\
\hline
\end{tabular}

Overall Enjoyment $2.34(1.01) \quad 2.31(.93) \quad .03$

Note. Response range: $5=$ very strongly; $1=$ very slightly or not at all. $\underline{\mathrm{df}}=24$.

$* \mathfrak{p}<.05 . * * \mathfrak{p}<.01$

Table 20, comprised of 11 items, represents the emotion of enjoyment (posited by Izard as the opposite of anxiety). overall, the change in this factor was negligible. However, the changes observed in the responses to 5 out of the 11 
adjectives items were statistically significant at the $\mathrm{p}<.05$ level and three of these were significant at the $\mathrm{p}<.01$ level (confident, relaxed and pleasant). The greatest changes were in pre- and post-test responses to pleasant $(.44)$ and confident (.24) versus smaller changes seen in content (.12) and relaxed $(.04)$. All statistically significant responses indicate a positive change in degree of emotional identification, and a decrease in variability within the respondent group between the pre- and the post-tests. 
Table 21

Pre \& Post-Test Differences and T-Scores for Questionnaire

Items Regarding surprise

Item

Pre-test $\underline{M}(\underline{\mathrm{SD}})$

Post-test Change

$\underline{t}$ $\underline{\text { M }} \underline{\mathrm{SD}})$

Amazed

$2.00(1.26) \quad 2.56(1.20) \quad .56 \quad 2.34 *$

Astonished

$2.16(1.32) \quad 1.88(1.11)-.28$

0

Surprised

$2.56(1.58)$

$2.52(1.20)-.04$ .69

Overall Surprise $2.24(1.39) \quad 2.32(1.17) \quad .08$

Note. Response range: $5=$ very strongly; $1=$ very slightly or not at all. $\underline{d f}=24$.

$* \underline{p}<.05 . * * \underline{p}<.01$

Table 21, which represents the combination of three questionnaire items that describe the emotion of surprise, showed results similar to those of the interest factor (Table 18). Only one item (amazed) showed a statistically significant change score $(\mathrm{p}=<.05)$. This item had the largest change score (.56) of any item in the questionnaire. The response to "amazed" increased in strength of emotional identification and decreased in variability among the respondent group from the pre- to the post-test. 
Table 22

Pre \& Post-Test Differences and T-Scores for Questionnaire Items Regarding Distress

Item

Pre-test

$\underline{\text { M }}(\underline{\mathrm{SD}})$

Post-test Change

$\underline{t}$

$\underline{M}(\underline{S D})$

Regretful

$1.60(1.02)$

$1.56(.94)$

$-.04$

$3 \cdot 15 * *$

Blameworthy

$1.36(.69) \quad 1.48(.90) \quad .12 \quad 6.19 * *$

Guilty

$1.56(1.02) \quad 1.60(.98)$

.04

0

Repentant

$2.16(.92)$

$1.84(.92)$

$-.32$

1.81

Downhearted

$$
2.16(1.05) \quad 1.88(.91) \quad-.32
$$

$2.18 *$

Upset

$1.92(1.16)$

$2.08(1.13)$

.16

$9.01 * *$

sad

$1.56(.94)$

$1.60(.75)$

.04

$3 \cdot 35 * *$

Discouraged

$2.04(.92)$

$1.80(.85) \quad-.24$

$2.89 * *$

\section{Overall Distress $1.80(.97) \quad 1.73(.92) \quad-.07$}

Note. Response range: $5=$ very strongly; $1=$ very slightly or not at all. $\underline{d f}=24$.

$* \underline{\underline{L}}<.05 . * 2 \mathrm{p}<.01$.

Table 22 represents 8 questionnaire items that describe the emotions of distress constructed by Izard as reflecting guilt and anxiety. While showing barely any change overall, this factor had the largest number of statistically significant changes between pre- and post-test of any other factor group. It also had a mixture of positive and negative change scores. 
The negative changes were found in responses to the adjectives downhearted $(-.32)$, repentant $(-.32)$, discouraged $(-.24)$ and regretful $(-.04)$, suggesting that participants felt less identification with these adjectives after reading the instructional handout. However, there were slight but significant increases in response to upset (.16), blameworthy (.12) and sad $(.04)$. The majority of the responses were significant at the $\mathrm{p}<.01$ level. Overall, post-test scores seemed to have less variation than did pre-test scores. 
Table 23

Pre \& Post-Test Differences and T-Scores for Questionnaire Items Regarding Anger

Item Pre-test Post-test Change $t$

\begin{tabular}{lcccc}
\hline Mad & $1.64(1.02)$ & $1.40(.75)$ & -.24 & .76 \\
Angry & $1.48(.81)$ & $1.36(.74)$ & -.12 & .21 \\
Disgusted & $1.44(.70)$ & $1.44(.64)$ & 0 & \\
Enraged & $1.44(.70)$ & $1.48(.75)$ & .04 & .58 \\
Scornful & $1.56(.94)$ & $1.56(.80)$ & 0 & \\
Contemptuous & $1.76(.91)$ & $1.52(.75)$ & -.24 & 1.57 \\
Feeling of Revulsion & $1.48(.75)$ & $1.52(.81)$ & .04 & 0 \\
& $1.48(.70)$ & $1.28(.45)$ & -.20 & $9.38 * *$ \\
Disdainful & $1.80(.94)$ & $1.48(.64)$ & -.32 & 1.97 \\
Feeling of Distaste & $1.56(.83)$ & $1.45(.70)$ & -.11 & \\
\hline
\end{tabular}

Note. Response range; $5=$ very strongly; $1=$ very slightly or not at all. $\underline{\mathrm{df}}=24$.

$* \underline{p}<.05 . * * \underline{p}<.01$.

Changes in only one of the 9 anger items, disdainful, was statistically significant (change=-.20, Table 23), which indicates a decrease in emotional identification. A decrease in variation in this significant response between the pre- 
and the post-tests existed.

other items in this factor showed potentially interesting change scores but these changes were not statistically significant. 
Table 24

Pre \& Post-Test Differences and $\mathrm{T}$-Scores for Questionnaire Items Regarding Shyness

Item Pre-test Post-test change $t$ $\underline{M}(\underline{S D}) \quad \underline{M}(\underline{S D})$

\begin{tabular}{lcccc} 
Shy & $1.60(.85)$ & $1.64(.79)$ & .04 & $3.53 * *$ \\
Bashful & $1.60(.85)$ & $1.56(.80)$ & -.04 & .38 \\
Sheepish & $1.40(.69)$ & $1.56(.70)$ & .16 & $4.74 * *$ \\
\hline Overall Shyness & $1.53(.80)$ & $1.59(.76)$ & .06 & \\
\hline
\end{tabular}

Note. Response range: $5=$ very strongly; $1=$ very slightly or not at all. $\underline{\mathrm{df}}=24$.

$* \underline{p}<.05 . * * \underline{p}<.01$

Table 24 represents the questionnaire adjectives indicating shyness. The change scores for two out of the three items (shy and sheepish) were significant at the $p<.01$ level. Both items showed a positive but relatively small change in emotional response (.04 and .16, respectively). Responses to the adjective shy showed less variation from the pre- to the post-test while responses to sheepish indicated a slight increase in variability. 
Table 25

Pre \& Post-Test Differences and T-Scores for Questionnaire Items Regarding Fear

Item Pre-test Post-test Change $\underline{t}$ $\underline{M}(\underline{S D}) \quad \underline{M}(\underline{S D})$

$\begin{array}{lllcl}\text { Nervous } & 2.64(1.02) & 2.40(1.13) & -.24 & 7.33 * * \\ \text { Tense } & 2.04(1.04) & 2.12(.91) & .08 & 4.06 * * \\ \text { Jittery } & 2.08(.98) & 1.76(.71) & -.32 & 2.36 * \\ \text { Fearful } & 2.24(1.07) & 2.28(.92) & .04 & 3.64 * * \\ \text { Afraid } & 2.56(1.24) & 2.20(1.02) & -.36 & 2.47 * \\ \text { Worried } & 2.88(1.11) & 2.56(1.10) & -.32 & 7.32 * * \\ \text { Scared } & 2.40(1.17) & 2.20(.80) & -.20 & 1.02\end{array}$

overexcited \& Rattled

\begin{tabular}{llccc} 
& $1.64(.79)$ & $1.52(.70)$ & -.12 & $9.15 * *$ \\
Anxious & $2.48(1.10)$ & $2.72(1.00)$ & .24 & $4.71 * *$ \\
High Strung & $2.00(1.02)$ & $1.72(.78)$ & -.24 & .50 \\
\hline Overall Fear & $2.30(1.05)$ & $2.15(.91)$ & -.15 & \\
\hline
\end{tabular}

Note. Response range: $5=$ very strongly; $1=$ very slightly or not at all. $\underline{\mathrm{df}}=24$.

$* \mathrm{p}<.05 . * * \mathrm{p}<.01$.

Table 25 displays changes in response to the adjectives associated with fear and anxiety. Responses to only two items (scared and high strung) did not show a significant change between the pre- and the post-test. 
The largest changes were in the pre- and post-test responses to afraid $(-.36)$, jittery $(-.32)$, worried $(-.32)$ and nervous $(-.24)$. With the exception of the latter, there was a decrease in variation associated with the responses to each of these adjectives suggesting that as a group, participants agreed in their decreasing identification with the terms afraid, jittery and worried after reading the handout. However, very slight but statistically significant increases in the means for tense and fearful can be seen. An even greater increase $(.24)$ can be seen in response to the adjective anxious. 
Table 26

Pre \& Post-Test Differences and $\mathrm{T}$-Scores for Questionnaire Items Regarding Fatigue

Item

Pre-test

$\underline{M}(\underline{S D})$

Post-test Change $\underline{t}$

\begin{tabular}{llllc}
\hline Sleepy & $2.48(1.24)$ & $2.12(.91)$ & -.36 & .31 \\
Fatigued & $2.60(1.17)$ & $2.28(.92)$ & -.32 & $2.04 *$ \\
Sluggish & $2.08(.93)$ & $1.92(.84)$ & -.16 & $2.71 *$ \\
\hline Overall Fatigue & $2.39(1.11)$ & $2.11(.89)$ & -.28 & \\
\hline
\end{tabular}

Note. Response range: $5=$ very strongly; $1=$ very slightly or not at all. $\underline{\mathrm{df}}=24$.

$* \mathrm{p}<.05 . * * \mathrm{p}<.01$.

Table 26, representing responses to the emotions associated with fatigue, shows results similar to those regarding shyness (Table 24). Three questionnaire items were combined for this table with two items, fatigued and sluggish, showing statistically significant changes. The specific significant change scores, fatigued (-.32) and sluggish $(-.16)$, suggest less identification with these adjectives between the pre- and post-test. Both also showed less variation at the post-test. 
Table 27

Pre \& Post-Test Differences and $T$-Scores for Questionnaire Items Regarding Calmness

Item

Pre-test $\underline{\mathrm{M}}(\underline{\mathrm{SD}})$

Post-test Change

$\underline{t}$ $\underline{M}(\underline{\mathrm{SD}})$

Calm

$3.16(.78)$

$2.84(.88)$

1.38

Note. Response range: $5=$ very strongly; $1=$ very slightly or not at all. $\underline{d f}=24$.

$* \underline{p}<.05 . * * \underline{p}<.01$.

The negative change in participants' responses to the adjective calm (Table 27) was not statistically significant although it had a relatively large change value (-.32) and an increase in variability. 
Table 28

Statistically Significant changes in Overall Means From Preto Post-Test (DES \& A Scale)

Positive Change

Negative Change

Blameworthy $(.69)$

Attentive $(-.40)$

Amazed (.56)

Afraid (-.36)

Pleasant (.44)

Worried (-.32)

Confident (.24)

Downhearted (-.32)

Anxious (.24)

Fatigued (-.32)

Upset (.16)

Jittery (-.32)

Sheepish (.16)

Discouraged (-.24)

Content (.12)

Nervous $(-.24)$

Tense (.08)

Disdainful (-.20)

$\operatorname{Sad}(.04)$

Sluggish (-.16)

Relaxed (.04)

Over-Excited \& Rattled(-.12)

Fearful (.04)

Regretful (-.04)

$\operatorname{Shy}(.04)$

Note. Includes only those factors in which the change in overall mean scores from pre- to post-test are statistically significant at the $\underline{p}<.05$ level.

In summary, the correlated t-test indicates that, while there was little change in. overall factor scores, of the 51 individual adjectives, $27(53 \%)$ received significantly different responses between the pre- and the post-test. 
These significant responses were distributed almost evenly between an increase and decrease in the strength of the respondents' identification with the emotion (Table 28). Most of these changes were in the expected direction although a few (i.e., increases in blameworthy, anxious and fearful) were not anticipated. 
Health Beliefs: Differences Between Pre- And Post-Test Scores

The same correlated $t$-test was used to analyze the changes in participants' responses to the health belief statements from the pre- to the post-test. The original five components of the health belief model (perceived severity, susceptibility, benefits, barriers, and self-efficacy) were analyzed together. As in the pre-test, six questions were then selected to form additional clusters representing perceived trust and health care provider communication. 
Table 29

Pre \& Post-Test Health Belief Cluster Differences and T-

Scores of Questionnaire Items Regarding Perceived Severity

Item

Pre-test Post-test Change

$\underline{t}$ $\underline{M}(\underline{S D}) \quad \underline{M}(\underline{S D})$

My diabetes will affect the health of my baby.

$$
3.00(1.23) \quad 3.44(1.02) \quad .44 \quad .71
$$

My diabetes will have a negative effect on my future health.

$$
2.48(.94) \quad 2.16(.78) \quad-.32 \quad .35
$$

My diabetes will cause me to be sick a lot.

$$
2.24(.81) \quad 2.24(.81) \quad 0
$$

Overall Perceived Severity

$$
2.57(.99) \quad 2.61(.87) \quad .04
$$

Note. Response range: $5=$ strongly agree; $1=$ strongly

disagree. $\underline{d f}=24$.

$* \underline{p}<.05 . * * \mathfrak{p}<.01$.

None of the differences in pre- and post-test responses to statements about the severity of GDM were statistically significant (Table 29). However, less variability was noted in the responses from the pre- to the post-test. 
Table 30

Pre \& Post-Test Health Belief Cluster Differences and T-Scores of Questionnaire Items Regarding Perceived Susceptibility. Item $\begin{array}{ccc}\text { Pre-test } & \text { Post-test } \\ \underline{M}(\underline{S D}) & \underline{M}(\underline{S D})\end{array}$

I will have diabetes for the rest of my life.

$$
1.84(.78) \quad 2.16(.73) \quad .32 \quad 4.16 * *
$$

My diabetes will be worse if I do nothing about it.

$$
4.40(.85) \quad 4.20 .94) \quad-.20 \quad .43
$$

Gestational Diabetes can be a serious disease if you don't control it. $\quad 4.12(.71) \quad 4.28(.87) \quad .16 \quad 1.43$

I feel more nervous about my pregnancy now then I did before my appointment. $3.28(1.22) \quad 3.24(1.18)-.04 \quad 1.40$

I am anxious about this pregnancy.

$$
3.48(1.17) \quad 3.64(.93) \quad .16 \quad 3.54 * *
$$

I am nervous about the consequences of this pregnancy.

$$
2.92(1.13) \quad 3.16(1.12) \quad .34 \quad 18.11 * *
$$

Overall Perceived Susceptibility

$$
3.34(.98) \quad 3.45(.96) \quad .11
$$

Note. Response range: $5=$ strongly agree; $I=$ strongly disagree. $\underline{d f}=24$.

$* \mathfrak{p}<.05 . * * \mathfrak{p}<.01$.

Table 30 represents respondents' beliefs about perceived susceptibility. This cluster had three items which 
demonstrated significant change between the pre- and posttest scores. These items asked respondents about the consequences of GDM (change=.34), having diabetes for life (change=.32) and anxiety about this pregnancy (change=.16) All three responses were significant at the $p<.01$ level and indicated the group's increasing agreement with statements regarding GDM's severity. Variation between the pre- and post-test scores dropped in all significant responses. 
Table 31

Pre \& Post-Test Health Belief cluster Differences and T-

Scores of Questionnaire Items Regarding Perceived Benefits.

Item

Pre-test Post-test Change $t$ $\underline{M}(\underline{S D}) \quad \underline{M}(\underline{S D})$

I can control the seriousness of my condition.

$$
3.92(.56) \quad 4.20(.57) \quad .28 \quad .78
$$

I am confident about my ability to maintain a healthy

$$
\text { pregnancy. } \quad 3.72(.83) \quad 3.72(.78) \quad 0
$$

I know that my physician will help me in making changes to manage my diabetes.

$$
3.88(.77) \quad 3.92(.74) \quad .04 \quad 2.72 * *
$$

I trust my physician to help me maintain a healthy pregnancy.

$$
4.16(.61) \quad 4.12(.65)-.04 \quad 3.03 * *
$$

I feel that my physician will assist me to have a healthy baby.
$4.04(.72)$
$4.16(.54)$
.12
$4.05 * *$

My doctor helped me understand my diabetes.

$$
2.72(92) \quad 2.96(1.08) \quad .24 \quad 2.88 * *
$$

Overall Perceived Benefits

$$
3.74(.73) \quad 3.85(.73) \quad .11
$$

Note. Response range: $5=$ strongly agree; $1=$ strongly

disagree. $\underline{d f}=24$.

$* \mathrm{p}<.05 . * * \mathrm{p}<.01$

Table 31 indicates that the changes in responses to all 
but one questionnaire item out of the six, the first one representing control of the condition, were statistically significant. The response to only one statement, I trust my physician, indicated a negative change. Responses to all the other statistically significant statements suggested a positive change.

The largest changes were represented by the statements regarding respondents' beliefs about the physician's assistance in understanding diabetes (change=.24) and assistance from the physician (.12). Less or no change was indicated by beliefs about physician's assistance in making changes (.04) and trust in the physician (-.04). In general, the degree of variability appeared to decrease or increase only slightly among responses. 
Table 32

Pre \& Post-Test Health Belief Cluster Differences and $T$ Scores of Questionnaire Items Regarding Perceived Barriers Item Pre-test $\underline{\text { M }}(\underline{\text { SD }})$ Post-test Change $\underline{t}$ $\underline{M}(\underline{S D})$

It will be difficult to make changes in my lifestyle while I am pregnant. $\quad 2.56(1.13) \quad 2.40(.89) \quad-.16 \quad .24$

I am uncertain of my ability to make all of the changes necessary to manage my diabetes.

$$
2.44(.98) \quad 2.68(1.01) \quad .24 \quad 2.05 *
$$

It seems like too many changes will be necessary to manage my

$$
\text { diabetes. } \quad 2.52(.64) \quad 2.24(.76)-.28 \quad 7.98 * *
$$

I don't understand what my physician tells me.

$$
2.24(1.24) \quad 2.12(.77) \quad-.12 \quad .23
$$

I am confused by what my doctor tells me.

$$
2.20(.89) \quad 2.12(.91) \quad-.08 \quad 4.92 * *
$$

Overall Perceived Barriers

$$
2.39(.98) \quad 2.31(.87) \quad-.08
$$

Note. Response range: $5=$ strongly agree; $1=$ strongly disagree. $\underline{d f}=24$. $* \underline{p}<.05 . * * \underline{p}<.01$.

The data in Table 32, which is made up of five health belief statements representing respondents' beliefs about barriers to care, are similar to the results of Table 30 with 
three questionnaire items that indicate statistically significant change values. The largest changes occurred in pre- and post-test responses to statements representing respondents' beliefs about GDM requiring too many changes $(-.28)$ and uncertainty of their ability to make changes (.24) versus a small change which occurred in the statement about confusion $(-.08)$. The variation among post-test scores appears to have increased in all significant responses as compared to pre-test scores. 
Table 33

Pre \& Post-Test Health Belief Cluster Differences and $T-$ Scores of Questionnaire Items Regarding Perceived Efficacy Item Pre-test $\underline{M}(\underline{S D})$ Post-test Change $\underline{t}$ $\underline{\text { M }}$ SD)

I believe I can control my diabetes.

$$
4.20(.63) \quad 4.20(.40) \quad 0
$$

Making changes is something one must do no matter how hard it is. $4.20(.57) \quad 4.24(.59) \quad .04 \quad 5.06 * *$

Overall Perceived Efficacy

$$
4.20(.60) \quad 4.22(.50) \quad .02
$$

Note. Response range: $5=$ strongly agree; $1=$ strongly disagree. $\underline{d f}=24$

$* \underline{p}<.05 . * * \underline{p}<.01$

Table 33 includes two questionnaire items that demonstrate the respondents' beliefs about self-efficacy. only differences in pre- and post-test responses to the second which asks about making changes (change=.04) was statistically significant but with minimal change scores. The post-test scores appeared to have considerably less variation than did the pre-test scores. 
Table 34

Changes in Health Beliefs Between Pre- and Post-Test Expected Changes Unexpected Changes

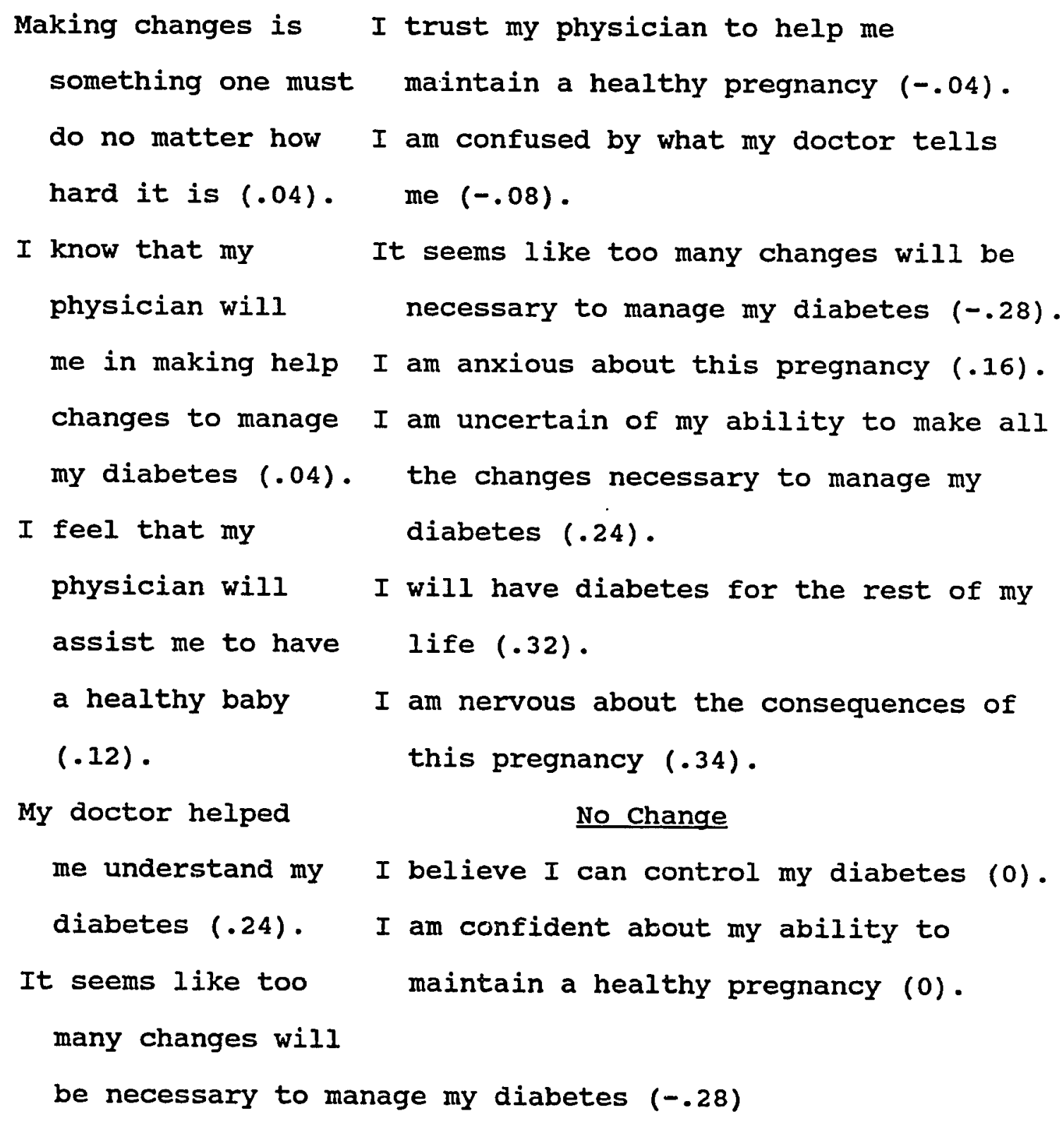

Note. Positive or negative change scores. Only statistically significant changes have been included. 
The correlated $t$-test indicates that there was a statistically significant change from the pre- to post-test scores on $60 \%$ (14 out of 22 ) of the health belief statements. These significant responses appear to be distributed more toward unexpected change (7) than expected change (5) (Table 34). Change scores for two key statements, one describing respondents' beliefs about confidence in maintaining a healthy pregnancy and the other regarding controlling diabetes, indicated no change at all between the pre- and post-test responses.

\section{Summary}

Analysis of anxiety and health beliefs in the pre- and post-test questionnaire indicates similar percentages (53\%, $60 \%$ ) of statistically significant changes after reading the instructional handout. Responses to statements from the health belief scale (Table 34) appear to be associated more with positive than negative feelings while the reverse is true with the DES \& A scale (Table 28). Two items from both scales indicated no change occurred between the pre- to the post-test. The degree of variability within all health belief clusters increased. 
CHAPTER 4

Discussion

Significance of the study

Gestational Diabetes Melitus (GDM) is a leading complication in pregnancy with an estimate of up to $12 \%$ of pregnant women developing the condition (Amankwah et al., 1977; Macupa, 1986; Forsbach et al., 1988). The complications that can result from uncontrolled GDM can be devastating. These complications include stillbirth, problems for the baby such as macrosomia, respiratory distress syndrome, and the increased risk that the mother may develop diabetes later in life.

The suffering and economic burden of diabetes has been found to be reduced by extensively instructing diabetics, especially those with GDM, in proper self-care. Preventive intervention by the woman with GDM can increase the chances of delivering a healthy infant. When a child's health is impaired the whole family suffers; society will also bear the cost, including medical expenses, loss of productivity and potential need for public assistance. Therefore, it is important that health care professionals intervene to prevent major perinatal problems in those areas where an investment of health care resources will stand to reap the greatest benefits (Macupa, 1986). Patient education, particularly self-care instruction, is one of those critical high-yield intervention points. 
Because educating the patient to self-care can be disrupted by anxiety we need to discover ways to decrease it. By doing so instruction can occur, compliance may increase and the potential for complications will be minimized. This study proposed a way to decrease anxiety in a cost effective way .

\section{Limitations}

There were several limitations that became apparent during the research process. It is important to realize that the data for this study were obtained under conditions of stress. These conditions include: the three-hour glucose tolerance test, the lack of knowledge on the part of the client, and the length of the testing process. This stress may have generated feelings different than those that would have been reported if the setting had been less stressful or unrelated to GDM and high risk pregnancy or both. The varying responses to the anxiety-related adjectives must be viewed in this light. However, it is important to remember that the researcher knew that women tended to be more anxious at this time and the measurement of this anxiety was what was intended by this study.

The first limitation that should be considered is that approximately $75 \%$ of the respondents did not know exactly what they were being tested for or why. This lack of knowledge may have created its own anxiety. Individuals may have felt unprepared and confused by the lack of information. 
When approached by the researcher, some individuals expressed concern about this unknown diagnosis and what it might mean to them. On the other hand, these questions may have encouraged them to participate in the study.

Another Iimitation is that the three-hour oral glucose tolerance test, with its frequent blood tests and three-hour waiting period, itself may have increased anxiety levels and affected test results. This test often makes individuals nauseous which also may affect their written test-taking ability.

The pre- and post-tests posed a problem. The individuals taking this test had not been definitively diagnosed with Gestational Diabetes, yet the questions asked the respondent to discuss feelings about having this condition. This may have created its own anxiety as the respondent may have learned about potential effects of the disease by reading the questionnaire. Not really knowing what the right answers were, or even being psychologicaliy prepared for this knowledge, may have aroused anxiety.

A design-related limitation is that there was no way to know if there were significant differences between those who did or did not complete the questionnaire. To obtain the sample of 25,32 individuals completed questionnaires. Incomplete questionnaires were eliminated. There was no way to separate the groups because consent forms, containing the only identifying information, could not be matched with 
anonymous questionnaires. Therefore, the retrospective chart review had to encompass all 32 who had consented, not just the 25 who actually completed questionnaires. If there was a demographic difference between these groups, it could not be determined.

Finally, the small size of the sample may not have adequately reflected pregnant women in the general population. Clients of the sunnyvale Medical clinic may not represent the entire pregnant population because only clients with resources, i.e., insurance or cash payment, are seen.

\section{Discussion of Results}

This study was based on the hypothesis that an instructional handout would decrease anxiety in the preliminarily diagnosed Gestational Diabetic. The data suggest both a confirmation and rejection of this hypothesis. A decrease in anxiety was indicated in the data from the DES \& A assessment while an increase in anxiety was noted with the results of the health belief assessment.

\section{Pre-Test Anxiety}

The pre-test was used to get a baseline on anxiety levels in this sample. The data from the pre-test showed some surprising patterns. Most overall scores on the DES \& A scale fell in the central to below central range (2.50-1.28) with very few statistically significant responses. When evaluating the responses it should be remembered that the minimum obtainable mean score for this scale is 1.00 , 
representing "very slightly or not at all."

Fatigue (Table 8 , overall pre-test $\underline{M}=2.39$ ) may have been affected by the time of the test, pregnancy itself and the actual testing. The test occurred first thing in the morning. Study participants usually arrived between 7:30 and 8:30 a.m. to begin the oral glucose tolerance test. This may have influenced several of the emotional responses. "Alert" and "attentive" scores, which were higher than the majority of adjective responses (Table 1), were not as high as might be expected. The test itself may have affected concentration. The individual often feels sick from the glucose (sugar) that she must drink, and because the test is early in the morning she may be tired. The enjoyment factor (Table 2, overall $\underline{M}=2.34$ ) registered lower than the interest factor (Table 1, overall $\mathrm{M}=3.03$ ). This is surprising given the assumed enjoyment of the state of pregnancy, but may have been influenced for the same reasons. Most likely, participants were responding, as instructed on the questionnaire, to the immediate situation and not their overall condition.

Also surprising were the low scores demonstrated in Table 3 (surprise, overall $M=2.24$ ), Table 4 (distress, overall $\underline{M}=1.80$ ) and Table 5 (anger, overall $\underline{M}=1.56$ ). It was expected that these values would have been higher as a result of having to go through the testing process and receiving the preliminary diagnosis of GDM. The low scores may indicate 
that this is not a serious limitation to the study. It is also possible that the positive feelings associated with pregnancy or the relatively non-threatening atmosphere of the clinic may have had an affect on these responses.

Fear (Table 7, overall $\underline{M}=2.30$ ), though fairly high for this sample, scored below interest and enjoyment. The emotion of calm (Table 9) had a high mean (3.16) with a relatively small degree of variation (.78) compared to the other factor groups.

The connotation of the 51 emotion adjectives and even the understanding of the meaning of these words may have affected scores. Many of the adjectives are not often used in every day vocabulary (i.e., repentant, downhearted and blameworthy) and subjects may not have fully understood them. An interesting test of the DES \& A scale occurred by accident. Due to a typing error on the post-test, the adjective fearful was printed twice, and responses were quite surprising. Ten out of the 25 respondents indicated different scores for that particular adjective on the same test. This has several important implications for the validity and reliability of this scale. Adjectives may not really register with respondents leading to superficial and inconsistent responses. The scale may be too long and respondents may become tired and lose interest in completing the test. Perhaps respondents feel overloaded with the steady stream of adjectives and become careless in their 
response. Any of these may result in the generation of potentially inaccurate data.

Separate from the instrument itself, it may be difficult to ascertain the actual emotions the pregnant individual is going through because pregnancy carries a unique set of emotional responses. In analyzing the data, it became evident that the DES \& A scale may not have been the most appropriate tool for testing anxiety because of the many factors that may affect the results. The scores appear to demonstrate that individuals do not identify with many of the emotions presented and suggest that respondents are not particularly anxious. The researcher knows that this is not the case because of the many questions and comments the respondents made throughout the testing period. Frequent questions included: 1) What does Gestational Diabetes mean to me?, 2) Will GDM hurt the baby?, 3) Was it something I did, or the food I ate? (I don't eat any sweets), and 4) Should I be worried?. Somehow this anxiety was not recorded by the DES \& A scale.

Pre-Test Health Beliefs

The health belief assessment yielded much higher pretest mean scores with less variability than appeared in the DES \& A factor groups. Individuals did appear to perceive GDM as severe (Table 11, overall $M=2.57$ ), and they perceived even stronger susceptibility (Table 12, overall $\underline{M}=3.34$ ). Perceived health benefits of compliance (Table 13, overall 
$\underline{M}=3.74$ ) outweighed the barriers (Table 14 , overall $\underline{M}=2.57$ ) by a considerable amount, and the highest scores were represented by respondents' feelings of self-efficacy (Table 15, overall $\underline{M}=4.20$ ).

The health belief questions related to trust received some of the highest scores by far of all the cluster groups combined (Table 16, overall $\underline{M}=4.03$ ). This appears to indicate the key role the physician plays in patient education. The health belief questions related to health care provider communication also point to the importance of the physician as a GDM educator. The responses indicated that respondents felt that they understand their physician but that he/she has not helped them understand their diabetes.

Pre- and Post-Test Comparison of Anxiety

Comparing the pre- to the post-test DES \& A responses, the data suggest that participants' anxiety levels appeared to decrease as a result of reading the instructional handout (Table 28). The data fell into some interesting patterns. Factor groups that describe the emotions of surprise (Table 21, overall change=.08), distress (Table 22, overall change=.07), shyness (Table 24 , overall change=.06) and enjoyment (Table 20, overall change=.03) all showed an increase in emotional response (Table 28). The scores for the emotion of enjoyment, which consisted of the individual adjectives pleasant (change $=.44$ ), confident (change=.24), 
content (change=.12) and relaxed (change=.04) were expected to increase due to the expanded knowledge provided by the instructional handout. This appears to have occurred as demonstrated by the positive changes represented. These data suggest that as their knowledge increased so did their confidence.

The adjective amazed (change $=.56$ ) was also expected to demonstrate an increase in emotional response due to the lack of knowledge in $75 \%$ of the study participants. Once again, the change figure indicates that identification with this emotion did increase. This most likely resulted from the participant discovering exactly what this diagnosis means and its effects to both herself and her baby.

Surprising responses were noted in relationship to the emotions of distress (upset (change=.16), blameworthy (change=.12) and sad (change=.04)) and anxiety (anxious (change=.24), tense (change=.08) and fearful (change=.04)) . The distress adjectives, upset, sad and blaneworthy, were expected to decrease due to an increase in knowledge. In particular, it was expected that identification with blameworthy would decrease since the instructional handout was intended to clarify that the individual was not to blame, but rather that the placenta caused this problem. However, the mother may have felt that the placenta is part of her body and therefore the onset of GDM is her fault. Although the pamphlet was designed to decrease anxiety, 
education or attainment of knowledge often can act to increase anxiety levels (Griesbach, 1985). Although unexpected, strong identification with the anxiety adjectives fearful, tense and anxious after reading the handout may be appropriate. Indeed, among fear adjectives, the degree of identification decreased more often (nervous, jittery, afraid, worried and over-excited/rattled) between the pre- and the post-test than increased (tense, fearful and high-strung, Table 26). Therefore, the responses to the DES \& A scale suggest that the expected decrease in anxiety from the pre- to the post-test did occur (overall change=-.15). However, this change was not nearly as large as had been expected.

At first it was difficult to understand why responses to the shyness adjectives of sheepish (change=.16) and shy (change=.04) increased. However, previous research has noted that high-risk pregnancies affect the social groups that the pregnant individual may be involved with (Schroeder-Zwelling \& Hock, 1986). Therefore it may not be inappropriate to associate new information about risk and potential problems with these particular adjectives.

There also were responses to the DES \& A scale that decreased in emotional response from the pre- to the posttest. The interest adjective of attentive decreased (change=-.40) which may represent some of the limitations of this study, i.e., not feeling well or the fact that the test 
was long. On the other hand, the fatigue adjectives of sluggish (change=-.16) and fatigued (change=-.32) also decreased which may indicate interest or response to the handout or the new information.

The emotions distress, fear and anger also indicated diminished emotional response. This is important because it suggests that the instructional handout was effective in decreasing not only fear represented by the adjectives of afraid (-.36), worried $(-.32)$, jittery $(-.32)$, nervous $(-.24)$ and over-excited/rattled (-.20), but also some of the individuals' distress associated with the adjectives of downhearted $(-.32)$, discouraged $(-.24)$ and regretful $(-.04)$ and anger indicated by the adjective disdainful (-.20) . Though there were many problems with the DES \& A tool, the responses indicate that the instructional handout did decrease anxiety levels among participants. The tool also identified changes in other important pregnancy and self-care related emotions that correspond with the findings from the second part of the questionnaire.

Pre- and Post-Test Comparison of Health Beliefs

In contrast to the decrease in anxiety following the educational intervention (indicated by the DES \& $A$ assessment), the data from the health belief section indicate a possible increase in anxiety from the pre- to the posttest. However, respondents identified in their responses to this assessment tool other important concepts, i.e., 
perceived trust, benefits of care and self-efficacy, with responses that indicated significant changes as a result of the instructional handout.

Each of the statements regarding perceived susceptibility (Table 30) received higher scores at posttest. The change scores for the statements which represent respondents' beliefs about nervousness regarding the consequences of this pregnancy (change=.34), having diabetes forever (change=.32) and anxiety about this pregnancy (change=.16) suggest that anxiety, as measured by this scale, did increase after reading the instructional handout. Respondents initially indicated that they felt strongly about the benefits of treatment (pre-test $\underline{M}=3.74$ ); this response increased after reading the handout (overall change=.11) (Table 31). Of the 5 responses that were statistically significant, three changed in a positive direction. These statements include beliefs about the doctor helping them to understand GDM (.24), the physician's assistance in having a healthy baby (.12) and in making changes $(.04)$. The respondents indicated a slightly diminished trust in thejx physician's assistance in maintaining a healthy pregnancy $(-.04)$. This may represent the feeling that many respondents had as a result of their physicians imparting little information regarding the diagnosis of GDM. It is important to remember that this perceived benefits section had the highest mean scores and 
the lowest variability for the health belief scale, so although there were positive and negative changes, respondents identified strongly with the benefits of selfcare and compliance.

The belief in the individual's self-efficacy began strong (pre-test $\underline{M}=4.20$ ) and remained strong (overall change=.02) (Table 33). Responses to the statement that making changes is necessary indicated a very slight positive change $(.04)$. It appears that the instructional handout reinforced this belief. The statement that "I believe I can control my diabetes" showed no change from the pre- to the post-test, but the mean remained high at 4.20 which suggests that this belief also was reinforced by the handout. In contrast, a belief statement about barriers to treatment (Table 32), which was the uncertainty about the ability to make all the necessary changes, increased in participant agreement (change=.24). This appears slightly contradictory to the previous statement. However, it is possible that an individual can feel that making changes is necessary and still feel unsure of her own ability to make those changes (HillBlakley, 1989). The purpose of the instructional handout was only to inform the reader of the necessary changes. It did not instruct them on the necessary techniques. Therefore, some uncertainty may be warranted and hopefully will be dispelled when the positively diagnosed individual receives Gestational Diabetes instruction. 
Two of the three statistically significant decreases correspond to statements about the respondents' beliefs in the potential barriers to treatment (Table 32, overall change score=-.08). The decreased agreement with the statements about the many changes that seem to be necessary (change=-.28) and confusion about what the physician communicates (change=-.12) actually were positive results of reading the instructional handout.

These data appear to suggest that the instructional handout was not only effective in diminishing the strength of perceived barriers but it also was effective in reinforcing and actually increasing the strength of perceived benefits. Therefore, although this scale indicated that anxiety increased as a result of the instructional handout, other very important beliefs were reinforced or introduced. Hopefully, these beliefs can and will aid not only the woman with GDM, but the health educator who instructs her as well, in the attainment of compliance to the prescribed regimen.

\section{Conclusions}

Anxiety as a subjective emotion is difficult to measure. However, the literature clearly states that not only does the diagnosis of diabetes increase anxiety levels (Fitzgerald, 1980) but that the changes an individual must make in lifestyle and self-care can do this as well (Holmes \& Masuda, 1974). Education has been demonstrated to not only help improve diabetes control significantly (Davidson et al., 
1976; Dunn, 1986; Macupa, 1986; Mazzuca et al., 1986) but also to decrease anxiety levels (Gilbert \& Harmon, 1986). Timing of education plays a crucial role in increasing learning and decreasing anxiety (Cohen, 1981; Griesbach, 1983).

This study attempted to evaluate anxiety levels in the preliminarily diagnosed Gestational Diabetic. The purpose of the study was to test the effectiveness of an instructional handout in decreasing anxiety and increasing positive, appropriate health beliefs.

Baseline anxiety was demonstrated among the respondents who participated in this study. The increase or decrease of these levels was evident, but was demonstrated in different ways by the two assessment tools used. These scales, the DES \& A anxiety scale and the adapted GDM-specific health belief scale, represented two distinct expressions of anxiety. The DES \& A scale dealt specifically with individual emotion adjectives and the respondent's degree of feeling right now, while the health belief scale probed the respondent's agreement with specific statements. Anxiety was found to decrease from the pre- to the post-test using the DES \& A scale while anxiety appeared to increase using the health belief scale. This may be explained, in part, by the methodological difference in responding to adjectives versus agreeing with statements.

The health belief assessment, though it indicated an 
increase in anxiety from the pre- to the post-test, also identified other important health beliefs, in particular the individuals' beliefs in the benefits of treatment and their own self-efficacy. The health belief model was developed to explain health-related behavior at the level of individual decision making hail, 1981). Creating an effective disease-specific scale will allow educators to determine clients' strengths and weakness so that these strengths can be effectively increased and weakness diminished.

The study results indicate that the respondents believed in the severity and susceptibility of their condition, the benefits of treatment and their own self-efficacy. Hurley (1989) believes that fundamental beliefs are strong motivators of human behavior. She goes a step further by stating that "one strategy to promote success with managing the diabetes regimen is for clinicians to devise an educational plan based on these beliefs" (p.44). It therefore becomes extremely important once again for the health educator to use this knowledge in designing an . effective teaching plan that will rely on these beliefs. Implications for Research

This study strongly suggests that individuals with the preliminary diagnosis of Gestational Diabetes do experience some anxiety, and that the instructional handout may be effective in decreasing anxiety and even in strengthening appropriate and positive health beliefs. Further study 
needs to be performed to determine the most appropriate time, circumstances and medium for providing clients with information necessary to decrease these anxiety levels.

For effective future research a GDM-specific DES \& Atype questionnaire needs to be designed to evaluate anxiety that deals with pregnancy and all its varied emotions. In this new scale the terms used will need to be updated. Finally, the original (but adapted) HBM tool needs to be tested for validity and reliability.

\section{Implications for Practice}

There are several implications for practice that must be explored. The data suggest that the instructional handout does provide some needed information. A brief handout may be more appropriate at the one-hour glucose tolerance test to provide clients with the appropriate information so that they know from the beginning what they are being tested for. This might eliminate the anxiety that develops as they wait for the results of the three-hour glucose tolerance test. Many clients also feel that the abnormal one-hour OGTT indicates that they already have the disease. since only approximately $3-12 \%$ of these individuals will develop the condition, this may not be the case. Therefore, this information, which also may be more beneficial in an expanded version, becomes extremely important.

The data indicate that respondents generally trust their physicians and feel that he/she will help them with 
any complication that may occur in pregnancy. Therefore, timing of GDM and self-care instruction by the physician is important. This further suggests that it might be very important to schedule the patient's three-hour OGTT just prior to their next appointment so that results can be given in person by the physician rather than via telephone. This would allow for discussion, initial instruction and further recommendations to be made at that time. Questions can be answered immediately by the obviously highly trusted physician, thereby allaying future anxiety.

Gilbert and Harmon (1986) gave other solutions to relieve anxiety. They stated that talking about the event can help identify, analyze, and understand the events causing anxiety. Group sessions in which pregnant women can discuss GDM and related events may be helpful. Fathers should be included whenever possible to assist in decreasing anxiety levels. This can be done by encouraging them to come with the woman to perinatal appointments or to the educational session itself. Gilbert and Harmon (1986) felt that couples who do not receive help together might otherwise increase each other's anxiety.

Anxiety does create certain problems to the preliminarily diagnosed Gestational Diabetic and needs to be resolved. Though this study did not show that the instructional handout decreased all of the patients' anxiety, it did appear to help. The findings clearly indicate that some form of 
educational information needs to be available, the exact timing, content and delivery mode need further evaluation. 


\section{References}

Adashi, E. Y., Pinto, H., \& Tyson, J. E. (1979). Impact of maternal euglycemia on fetal outcome in pregnancy. American Journal of Obstetrics and Gynecology, 133, 268-278.

Alogna, M. (1980). Perception of severity of disease and health locus of control in compliant and noncompliant diabetic patients. Diabetes Care, 3, 533-534.

Alpert, R., \& Haber, R. M. (1960). Anxiety in academic achievement situations. Journal of Abnormal and Social Psychology, 61, 207-215.

Amankwah, K. S., Prentice, R. L. \& Fleury, F. J. (1977) . Incidence of gestational diabetes. Obstetrics and Gynecology, 49, 497-498.

Arakelian, M. (1980). An assessment and nursing application of the concept of locus of control. American Nursing Science, $3,25-42$.

Bandura, A. (1986). Self-efficacy: Toward a unifying theory of behavioral change. Psychological Review, 84 (2), 191-215.

Bandura, A. (1977). Social learning theory. Englewood, New Jersey: Prentice Hall.

Baric, L. (1969). Recognition of the "at risk" role: A means to influence health behavior. International Journal of Health Education, 12, 24-34.

Barglow, P., Hatcher, R., Edidin, D. V., \& Sloan-Rossiter, D. (1984). Stress and metabolic control in diabetes: Psychosomatic evidence and evaluation of methods. Psychosomatic Medicine, 46(2), 127-143.

Barofsky, I. (1978). Compliance, adherence and the therapeutic alliance: steps in the development of selfcare. Social Science and Medicine, 12, 369-376.

Basowitz, H., Persky, H., Korchin, S.J., \& Grinkler, R. R. (1955). Anxiety and stress. New York: McGraw-Hili.

Becker, M. H. \& Janz, N. K. (1985). The health belief model applied to understanding diabetes regimen compliance. The Diabetes Educator, 3 , 41-47. 
Becker, M. H., Radius, S. M., Rosentsock, I. M., Drachman, R. H. , Schuberth, L. C., \& Teets, K. T. (1978). Compliance with a medical regimen for asthma: A test of the health belief model. Public Health Reports, 93, 268-277.

Braveman, P., Showstack, J., Browner, W., Selby, J., Teutsch, S., \& Sepe, S. (1988). Evaluating outcomes of pregnancy in diabetic women: Epidemiologic considerations and recommended indicators. Diabetes Care, 11(3), 281-287.

Caplan, G. (1975). Psychological aspects of pregnancy. In $\mathrm{N}$. Leif (Ed.), The pyschologic basis of medical practice (pp. 256-272). New York: Harper and Row.

Cerkoney, K. A., \& Hart, L. K. (1980). The relationship between the health belief model and compliance of persons with diabetes mellitus. Diabetes Care, $\underline{3}(5)$, 594-597.

Cohen, S. A. (1981). Patient education: A review of the 1iterature. Journal of Advanced Nursing, $\underline{6}(1), 11-18$.

Coustan, D. R., \& Imarah, J. (1984). Prophylactic insulin treatment of gestational diabetes reduces the incidence of macrosomia, operative delivery, and birth trauma. American Journal of Obstetrics and Gynecology, 150, 836-840.

Coustan, D. R., Lewis, S. B. (1978). Insulin therapy for gestational diabetes. Obstetrics and Gynecology, 51, 306310.

Coustan, D. R., widness, J. A., Carpenter, R. W., Rotondo, L., Pratt, D. C., \& Oh, W. (1986). Should the fifty-gram, one hour plasma glucose screening test for gestational diabetes be administered in the fasting or fed state? American Journal of Obstetrics and Gynecology, 154, 10311035 .

Davidson, J. K., Alogna, M., Goldsmith, M., \& Riley, J. (1974). Assessment of program effectiveness at Grady Memorial hospital. In Report of the National Commission on Diabetes to the Congress of the United States. (DHEW Publication No. IH 76-1018). Washington, D. C., United States Publishing office, 3-parts, 227-249.

Davis, M. S. (1967) . Predicting non-compliant behavior. Journal of Health and Social Behavior, $\underline{8}, 265-271$.

DeFriese, G. H., Woomert, A., Guild, P. A., Steckler, A. B., \& Konrad, T. R. (1989). From activated patient to pacified activist: A study of the self-care movement in the United states. Social Science and Medicine, 29(2), 195-204. 
Dunn, S. M. (1986). Reactions to educational techniques: Coping strategies for diabetes and learning. Diabetic Medicine, 3 , 419-429.

Dunn, S. M. (1988). Treatment-Education. Bailliere's Clinical Endocrinology and Metabolism, 2, 493-505.

Dyer, E. E. \& Chalfant, A. L. (1978). Factors effecting diabetic client knowledge. Communicating Nursing Research, Volume 11: New approaches to communicating research. Boulder, colorado: Western Interstate Commission for Higher Education.

D'Zurilla, T. J., \& Goldfried, M. R. (1971). Problem-solving and behavior modification. Journal of Abnormal Psychology, 78, 107-126.

Farrell, J., Forrest, J. M., Storey, G. N. B., Yue, D. K. Shearman, R. P. \& Turtle, J. R. (1986). Gestational diabetes-infant malformations and subsequent maternal glucose tolerance. Australian and New Zealand Journal of obstetrics and Gynecology, 26(11), 11-16.

Fitzgerald, S. (1980). Utilizing orem's self-care nursing model in designing an educational program for the diabetic. Topics in clinical Nursing, $\underline{2}(2), 57-65$.

Forsbach, G., Contreras-Soto, J. J., Fong, G., Flores, G. \& Moreno, O. (1988). Prevalence of gestational diabetes and macrosomic newborns in a Mexican population. Diabetes Care, 11(3), 235-238.

Freinkel, N., Metzger, B. E., Phelps, R. L., Dooley, S. L., Ogata, E. S., Radvany, R. M. \& Belton, A. (1985). Gestational diabetes mellitus: rieterogeneity of maternal age, weight, insulin secretion, HLA antigens, and islet cell antibodies and the impact of maternal metabolism on pancreatic B-cell and somatic development in the offspring. Diabetes, 34 (Suppl.2), 1-7.

Freud, S. (1924). The problem of anxiety. New York: Norton.

Gabbe, S. G., Mestman, J. H., Freeman, R., Anderson, G. V., \& Lowensohn, R. I. (1977). Management and outcome of class A diabetes mellitus. American Journal of Obstetrics and Gynecology, 127, 465-469.

Galloway, K. (1976). The uncertainty and stress of high risk pregnancy. American Journal of Maternal Child Nursing, $\underline{5}, 294-299$. 
Gessner, B. A. (1989). Adult education: The cornerstone of patient teaching. Nursing clinics of North America, 24 (3), 589-627.

Gilbert, E. S. \& Harmon, J. S. (1986). High-risk pregnancy and delivery. St. Louis: The C.V. Mosby Company, 69-82.

Given, C. W., Given, B. A., Gallin, R. S. \& Condon, J. W. (1983). Development of scales to measure beliefs of diabetic patients. Research in Nursing and Health, $\underline{6}$, 127-141.

Goldberg, J. D., Franklin, B., Lasser, D., Jornsay, D. I., Hausknecht, R. L., Feliner, F., \& Berkowitz, R. L. (1986). Gestational diabetes: Impact of home glucose monitoring on neonatal birth weight. American Journal of Obstetrics and Gynecology, 154(3), 546-550.

Goldfried, M. R. \& Goldfried, A. P. (1975). Cognitive change methods. In F. H. Kanfer \& A. P. Goldstein (Eds.), Helping People Change. New York: Pergamon.

Goulet, L. R. (1968). Anxiety (drive) and verbal learning: Implications for research and some methodological considerations. Psychological Bulletin, 69, 235-247.

Grant, P. T., Oats, J. N. \& Beischer, N. A. (1986). The long-term follow-up of women with gestational diabetes. Australian and New Zealand Journal of obstetrics and Gynecology, 26(17), 17-21.

Griesbach, E. H. (1985). Anxiety and the timing of diabetes teaching in the hospital: A literature review. The Diabetes Educator, 4, 43-45.

Guzzeta, C. E. (1979). Relationship between stress and learning. Advances in Nursing Science, $1(4), 35-49$.

Haefner, D., \& Kirscht, J. P. (1970). Motivational and behavioral effects of modifying health beliefs. Public Health Report, 85, 478-484.

Hamilton, H. (1983) . Nurse's Reference Library Series: Definitions. Springhouse, Pennsylvania; Intermed Communications, Inc.

Heins, H. C. \& Keane, R. (1981). High risk pregnancy prevention management. Garden City, New York; Medical Examination Publications Company. 
Hill-Blakey, L. (1988). Gestational diabetes. Childbirth Educator, 4, 24-29.

Hoet, J. J. (1980). Effect of intervention in gestational diabetes. Diabetes Care, $\underline{3}(3), 497-498$.

Hollander, P. (1988). Gestational diabetes: The diabetes of pregnancy. Practical Diabetology, I(2), 14-19.

Holmes, D. M. (1986). The person and diabetes in psychosocial context. Diabetes Care, $9(2), 194-206$.

Holmes, T. H. \& Masuda, M. (1974). Life change and illness susceptibility. In B.S. Dohrenwend \& B.P. Dohrenwend (Eds.). Stressful life events: Their nature and effects (pp.154-212). New York: John Wiley \& Sons.

Howard, M., Barneti, C., Chon, M., \& Wolf, F. M. (1986). Retention of knowladge and self care skills after an intensive in-patient diabetes education program. Diabetes Research and Clinical Practice, 2 , 51-57.

Huckabay, L. M. S. (1980) . A strategy for patient teaching. Nursing Administration Quarterly, $4(2), 47-54$.

Hulka, B. S., Kupper, L. L., Cassel, J. C., \& Mayo, F. (1975) : Doctor-patient communication and outcomes among diabetic patients. Journal of Community Health, $1,15-27$.

Hurley, A. C. (1989). The health belief model: Evaluation of a diabetes scale. The Diabetes Educator, 16, 44-48.

Izard, C. E. (1972). Patterns of emotions: A new analysis of anxiety and depression. New York: Academic Press.

Jones, F. G. (1979). The high risk pregnancy. In S. H. Johnson (Ed.), High risk parenting: Nursing assessment and strategies for family at risk (pp.81-93). New York: Lippincott.

Kasl, S. V. (1974). The health belief model and behavior related to chronic illness. Health Education Monographs, winter, 433-449.

Kirscht, J. P., \& Rosenstock, I. M. (1977). Patient adherence to antihypertensive medical regimens. Journal of Community Health, $\underline{3}, 115-124$.

Krause, M. S. (1961). The measurement of transitory anxiety. Psychology Review, 68, 178-189. 
Krohne, H. W. \& Laux, L. (1982). Achievement, stress, and anxiety. New York: Hemisphere Publishing Corporation.

Lam, K. S. L., Ma, J, \& Yeung, R. (1986). Sustained improvement in diabetic control on long term selfmonitoring of blood glucose. Diabetes Research and Clinical Practice, $\underline{2}$, 165-171.

Lavin, J. P., Lovelace, D. R., Miodovinick, S., Knowles, H. C., \& Barden, T. P. (1983). Clinical experience with one hundred seven diabetic pregnancies. American Journal of Obstetrics and Gynecology, 147, 158-162.

Leavitt, F. (1979). The health belief model and utilization of ambulatory care services. Social Science and Medicine, $13 \mathrm{~A}, 105-112$.

Leventhal, H. (1970). Findings and theory in the study of fear communication. In Berkowitz, L. (Ed.), Advances in Experimental Psychology (pp.268-302). New York: Academic Press.

Levitt, E. E. (1967). The psychology of anxiety. Indianapolis: Bobbs-Merrill Company, Inc.

Lockington, T. J., Powles, S., Meadows, K. A., \& Wise, P. H. (1989): Attitudes, knowledge and blood glucose control. Diabetic Medicine, $\underline{6}, 309-313$.

Lorr, M. \& MCNire, D. (1982). Profile of mood states: Bipolar form. San Diego, California: Educational and Industrial Testing Service.

Luckton, R. (1974) . Crisis theory: Review and critique. Social Science Review, 48, 384-402.

Macupa, L. (1986). A proposal for detecting and managing gestational diabetes by coordinating existing services. public Health Reports, 101(1), 94-97.

Mahoney, M. J. (1974). Cognition and behavior modification. Cambridge, Massachusetts: Ballinger.

Maiman, L. A., Becker, M. H., Kirscht, J. P., Haefner, D. P., \& Drachman, R. H. (1977). Scales for measuring health belief model dimensions: A test of predicative value, internal consistency, and relationships among beliefs. Health Education Monographs, 4, 215-230. 
Mandler, G. \& Watson, D.C. (1966). Anxiety and the interruption of behavior. In C.D. Spielberger (Ed.), Anxiety and Behavior (pp.463-552). New York: Academic Press.

Manning, M. M. , \& Wright, T. L. (1983). Self-efficacy expectancies, outcome expectancies, and the persistence of pain control in childbirth. Journal of Personality and Social Psychology, $45(2), 421-431$.

Mazzuca, S. A., Moorman, N. H., Wheeler, M. L., Norton, J. A., Fineberg, N. S., Vinicor, F., Cohen, S. J., \& Clark, C. M. (1986). The diabetes education study: A controlled trial of the effects of diabetes patient education. Diabetes Care, 9 (1), 1-10.

Miesenhelder, J. B. (1987). Anxiety: A block to clinical learning. Nurse Educator, 12(6), 27-30.

Mikhail, B. (1981). The health belief model: A review and critical evaluation of the model, research, and practice. Advanced Nursing Science, $\underline{4}(1), 65-79$.

Miller, J. M. (1983). A reappraisal of "tight control" in diabetic pregnancies. American Journal of obstetrics and Gynecology, 147, 158-162.

Miller, L. V. \& Goldstein, J. (1972). More efficient care of diabetic patients in a county hospital setting. New England Journal of Medicine, 286, 1388-1391.

Miller, L. V., Goldstein, J., \& Nicolaisen, G. (1978). Evaluation of patient's knowledge of diabetes self-care. Diabetes Care, 1 , 275-280.

Mills, J. I. (1982). Malformations in infants of diabetic mothers. Teratology, 25(3), 385-394.

Nersesian, W., \& Zaremba, M. (1982). Impact of diabetes outpatient education program - Maine. Morbidity and Mortality Weekly Report, 31(23), 307-309.

Oats, J. N. \& Beischer, N. A. (1985). Gestational diabetes. Australian and New Zealand Obstetrics and Gynecology, $\underline{26}(2), 2-9$.

O'Sullivan, J. B. (1978). Establishing criteria for Gestational diabetes. Diabetes Care, 3(3), 437-439. 
Pedersen, J. (1978). Congenital malformations in newborns of diabetic mothers. In Sutherland, H.W. \& Stowers, J.M. (Eds.) - Carbohydrate Metabolism in Pregnancy and the Newborn (pp.127-138). Springerlag, Berlin, Heidelberg, New York: Butler and Tanner, Rtd.

Peplau, H. (1957). Therapeutic concepts in aspects of psychological nursing. League Exchange, 26B, 12-15.

Philipson, E. H. \& Super, D. M. (1989). Gestational diabetes mellitus: Does it recur in subsequent pregnancy? American Journal of Obstetrics and Gynecology, 160, 1324-1331.

Plehwe, W.E., Storey, G. N., Shearman, R. P. \& Turtle, J. R. (1984). Outcome of pregnancy complicated by diabetes: Experience with 232 patients in a 4 year period. Diabetes Research, $1(2), 67-73$.

Raz, I., Soskoline, V., \& stein, P. (1988). Influence of small-group education sessions on glucose homeostasis in NIDDM. Diabetes Care, 11(1), 67-71.

Rosenstock, I. M. (1985) . Understanding and enhancing patient compliance with diabetic regimens. Diabetes Care, $\underline{8}(6)$, 610-616.

Rubin, R. (1976). Forward, in Clark, A. \& Affonso, D. Childbearing: A Nursing Perspective. Philadelphia; F. A. Davis Company.

Sackett, D. L. (1976). The magnitude of compliance and noncompliance. In D. I. Sackett \& R. B. Haynes (Eds.), Compliance with therapeutic regimens (pp. 344-352). Baltimore: John Hopkins University Press.

Sarason, S. B. (1972). Some correlates of test anxiety. Journal of Abnormal and Social Psychology, 47, 810-817.

Schlenk, E. A. \& Hart, L. K. (1984). Relationship between health locus of control, health value, and social support and compliance of persons with diabetes mellitus. Diabetes Care, I (6), 566-574.

Schroeder-Zwelling, K., \& Hock, C. (1986). Maternal anxiety and sensitive mothering behavior in diabetic and nondiabetic women. Research in Nursing and Health, 9, 249255 .

Second International Workshop-Conference on Gestational Diabetes. (1985). Summary and recommendations. Diabetes, 34 (Suppl. 2), 123-126. 
Sieber, J. E., O'Neil, H. F., \& Tobias, S. (1977). Anxiety, learning, and instruction. New Jersey: Lawrence Erlbaum Associated, Publishers.

Snyder, D. J. (1979). The high-risk mother viewed in relation to a holistic model of the childbearing experience. Journal of Obstetrics and Gynecological Nursing, May-June, $\frac{164-170 \text {. }}{6}$

Spence, J. T., \& Spence, K. W. (1966). The motivational components of manifest anxiety: Drive and drive stimuli. In C.D. Spielberger (Ed.), Anxiety and Behavior (pp. 291326). New York: Academic Press.

Spielberger, C.D. (1972). Anxiety: Current trends in theory and research. New York: Academic Press.

Spirito, A., williams, C., Ruggiero, I., Bond, A., McGarvey, S. T. \& Coustan, D. (1989). Psychological impact of the diagnosis of gestational diabetes. obstetrics and Gynecology, 73 (4), 562-565.

Taber, C. W. (1972). Taber's Cyclopedic Medical Dictionary. Philadelphia; F. A. Davis Company.

Wine, J. D. (1971). Test anxiety and direction of attention. Psychological Bulletin, 76, 92-104. 


\section{PLEASE NOTE:}

Copyrighted materials in this document have not been filmed at the request of the author. They are available for consultation, however, in the author's university library.

These consist of pages:

$126-127$ 


\section{Appendix B}

\section{Health Belief Pre-Test Questionnaire}

Listed below are a set of questions that describe feelings about gestational diabetes. Once again, please rate your feelings by circling the appropriate statement:

1- strongly disagree

2- disagree

3- undecided

4- agree

5- strongly agree

1. I will have diabetes for the rest of my life. $\begin{array}{lllll}1 & 2 & 3 & 4 & 5\end{array}$

2. My diabetes will affect the health of my baby. $\begin{array}{lllll}1 & 2 & 3 & 4 & 5\end{array}$

3. My diabetes will be worse if I do nothing about it.

4. I don't understand what my physician tells me.

5. Gestational diabetes can be a serious disease

if you don't control it.

6. My diabetes will have a negative effect on my future health.

$\begin{array}{lllll}1 & 2 & 3 & 4 & 5\end{array}$

7. My diabetes will cause me to be sick a lot. $\begin{array}{lllll}1 & 2 & 3 & 4\end{array}$

8. I believe I can control my diabetes.

12345

9. It will be difficult to make changes in my lifestyle while I'm pregnant.

12345

10. I am confused by what my doctor tells me.

12345

11. I am confident about my ability to maintain a healthy pregnancy. 
12. I trust my physician to help me maintain a healthy pregnancy.

13. I am uncertain of my ability to make all of the changes necessary to manage my diabetes. $\quad \begin{array}{lllll}1 & 2 & 3 & 4 & 5\end{array}$

14. It seems like too many changes will be necessary to manage my diabetes.

15. Making changes is something that one must do no matter how hard it is.

$\begin{array}{lllll}1 & 2 & 3 & 4 & 5\end{array}$

16. My doctor helped me understand my diabetes.

12345

17. I can control the seriousness of my condition. 12345 18. I am anxious about this pregnancy. $\begin{array}{lllll}1 & 2 & 3 & 4 & 5\end{array}$

19. I know that my physician will help me in making changes to manage my diabetes.

20. I feel more nervous about my pregnancy now than I did before my appointment.

21. I feel that my physician will assist me to have a healthy baby.

22. I am nervous about the consequences of this pregnancy. 
130

Appendix C

SUNMYVALE MEDICAL CLINIC. INC. MEMORANDUM

To: Bonnie F. Hirsech

Date: $\quad 9 / 12 / 89$

RE! MPH Thesis topic appered by Drs. Filipand Lewis

Authorization for research to be completed at the Sunnyvale Medical Clinic given by: Petark. Tenputy

Date: $9 / 12 / 89$

Prom the desk of

Occupational Health Division 755 Nonth Posioria. Sunnyvale 7:30 am. - 4.00 p.m. MON.FN (408) 733-4380
Urgent Core Center 201 Old Son Froncisco Rood. Sunnyole $8.30 \mathrm{am}$ - 10.00 p.m. EVERYDAY (408) $730-4300$
Sonto Cloro Medicol Center 2794 El Comino Real ar Kiely Btud. Sonio Cloro B:30 am. 10:00 p.m EVERYDAY (408) 241-3038
Sunnywale Medicol Clinie Ine 596 Conoll Sreet. Sumnvole 8:30 am - 6.00 pm AON.FN $8: 30 \mathrm{am} \cdot 1: 00$ p.m SAT (408) 739-0551
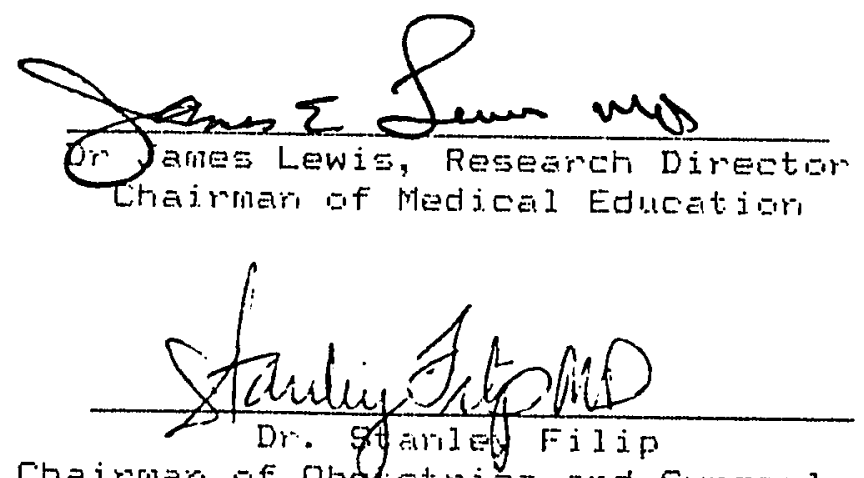

Chairman of obdietrics ard oynecalogy

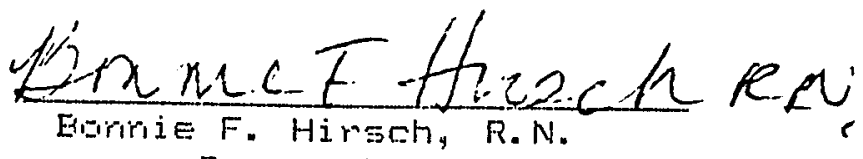

Reseancher 
Appendix D

To: Bonnie Coplon-Hirsch, Health Science

From: Charles R. Bolz

Office of Graduate Studies and Research

Date: October 9, 1989

The Human Subjects Institutional Review Board has approved your request to use human subjects in the study entitled:

"Effectiveness of an instructional hand-out on anxiety levels in the preliminarily diagnosed gestational diabetic".

This approval is contingent upon the subjects participating in your research project being appropriately protected from risk. This includes the protection of the anonymity of the subjects' identity when they participate in your research project, and with regard to any and all data that may be collected from the subjects. The Board's approval includes continued monitoring of your research by the Board to assure that the subjects are being adequately and properly protected from such risks. If at any time a subject becomes injured or complains of injury, you must notify Dr. Serena stanford immediately. Injury includes but is not limited to bodily harm, psychological trauma and release of potentially damaging personal information.

Please also be advised that each subject needs to be fully informed and aware that their participation in your research project is voluntary, and that he or she may withdraw from the project at any time. Further, a subject's participation, refusal to participate or withdrawal will not affect any services the subject is receiving or will receive at the institution in which the research is being conducted.

If you have any questions, please contact Dr. stanford or me at $4-2480$. 


\section{Appendix E \\ Consent Form}

AGREEMENT TO PARTICIPATE IN RESEARCH

RESPONSIBLE INVESTIGATOR: BOnnie F. Hirsch, R.N.

TITLE OF PROTOCOL: Anxiety levels in the preliminarily

diagnosed Gestational Diabetic.

I have been asked to participate in a research study that is investigating knowledge and anxiety among pregnant women being tested for Gestational Diabetes. The results of this study should further our understanding of the experience of women receiving this diagnosis, the effectiveness of educational interventions and the optimal organization of prenatal health care services.

I understand that:

1) I will be asked to complete a written questionnaire, read an instructional pamphlet, and then complete another questionnaire. Each questionnaire will take approximately 20 minutes.

2) There are no physical risks to this study.

3) The possible benefits of this study are that, based on study activities, I may not be as anxious about the diagnosis of gestational diabetes.

4) The results from this study may be published, but any information from this study that can be identified with me will remain confidential and will be disclosed only with my permission or as required by law. 
5) Any questions about my participation in this study will be answered by Bonnie F. Hirsch, (408-730-4360) or Dr. Kathleen Roe, (408-924-2976). For questions or complaints about research subject's rights, or in the event of research-related injury, contact serena stanford, Ph.D. (Associated Academic Vice President for Graduated Studies) at 408-277-2943.

6) My consent is given voluntarily without being coerced; I may refuse to participate in this study or in any part of this study, and I may withdraw at any time, without prejudice to my relations with SJSU or the sunnyvale Medical clinic.

7) I have received a copy of this consent for my records. I HAVE MADE A DECISION WHETHER OR NOT TO PARTICIPATE. MY SIGNATURE INDICATES THAT I HAVE READ THE INFORMATION PROVIDED ABOVE AND THAT I HAVE DECIDED TO PARTICIPATE. 


\section{PLEASE NOTE:}

Copyrighted materials in this document have not been filmed at the request of the author. They are available for consultation, however, in the author's university library.

These consist of pages:

$134-135$ 
Appendix G

Text of Instructional Handout*

The diagnosis of Gestational Diabetes Mellitus

(GDM) often increases the fear and anxiety that a woman may already be experiencing with an otherwise normal

pregnancy. This pamphlet is designed to decrease your

fears and to assist you in making your pregnancy a happy and healthy one.

O.K., some facts about GDM. GDM occurs during pregnancy and disappears in $98 \%$ of women with this diagnosis soon after the baby is born. It affects up to $10 \%$ of all pregnancies, making it the most common medical complication of pregnancy today. GDM can occur in subsequent pregnancies and $60 \%$ of women who have had GDM and who are overweight may develop Type 11 diabetes (Adult onset, non-insulin dependent diabetes) later in life. By maintaining a normal or near normal body weight, your chances of developing further diabetes decreases to only $25 \%$ depending on your family history.

GDM usually is not detected until the late second or early third trimester of pregnancy when it can be detected by a routine lab test. As you have already experienced, the initial test is called a one-hour oral glucose tolerance test *During data collection, this text was presented in a seven page booklet with a bright green cover and bold cover graphics. 
(OGTT). You are here because your sugar level came back higher than $140 \mathrm{mg} / \mathrm{dl}$. The next step is the formal OGTT or the three-hour OGTT. Normal levels vary during the three hours, but two measurements higher than $105 \mathrm{mg} / 100 \mathrm{ml}$ fasting, $190 \mathrm{mg} / 100 \mathrm{ml}$ at one hour, $165 \mathrm{mg} / 100 \mathrm{ml}$ at two hours, or $145 \mathrm{mg} / 100 \mathrm{ml}$ at three hours or any sugar in the urine indicates the presence of GDM.

The major cause of GDM is the normal and very necessary change in certain hormone levels produced by the placenta during pregnancy. The increased levels of placental lactogen, estrogen and progesterone impair the action of insulin on blood sugar. As a result, blood glucose rises. Insulin, produced in the pancreas, aids in the metabolism of sugar. During pregnancy, the pancreas has to increase its production of insulin 2 to 3 times that of pre-pregnancy levels. Normally, your pancreas will increase production of insulin to compensate for the increased levels of blood glucose. In women with GDir, the pancreas cannot make enough insulin to meet these needs resulting in abnormally high levels of sugar in the blood.

GDM often occurs in women without any risk factors. It is important to be aware that the risk of developing GDM is greater in those women who have a family history of diabetes, who are overweight, who are over 30 , or who have had babies larger than 9 pounds. Women with gestational diabetes rarely experience the typical symptoms of diabetes - weakness, 
thirst, hunger, and a frequent need to urinate. since these are also common characteristics of pregnancy itself, even when they occur, they can easily be dismissed. Many women report no symptoms at all. This is why routine testing of all pregnant women has become so important. The American Diabetes Association and the American College of Obstetricians and Gynecologists recommend routine GDM testing for all pregnant women between 24 and 28 weeks of pregnancy. Blood sugar control becomes extremely important in preventing complications of GDM and is something you can do! However, there are several potential complications of GDM that are important to be aware of. Excessive amounts of sugar can pass through the placenta causing the fetus to produce more insulin which in turn causes it to grow large (macrosomia). Babies are not born with diabetes. The result of this extra sugar, and the baby's insulin production, is that the baby may go through a sugar withdrawal at birth. To treat this problem of low blood sugar (hypoglycemia) the baby will either be placed on sugar water and then weaned (if stable) or placed on an "IV" (intravencus line) and be watched carefully for a few days. Consequently, controlling the mother's blood sugar level becomes important for the baby's well being. Another serious risk is fetal death. Although the reasons are unclear, inadequate control of maternal blood sugar appears to impair the functioning of the placenta, usually in the last month of pregnancy. This is 
avoided when blood sugars are kept within a normal range. Jaundice (hyperbilirubinemia) or yellowing of the skin occurs more frequently in the babies of women with GDM. This condition is easily treated by placing the baby under a special light. Very rarely, the jaundice becomes so severe that the baby needs a blood transfusion. Now, you are probably wondering what can happen to you as a result of this condition. Some women with GDM develop too much amniotic fluid in the uterus (polyhydramnios). This can cause early labor because the extra fluid stretches the uterus. If the labor is not stopped, the baby may be born prematurely. Another problem is that having a large baby is not easy. It may prolong your labor because the baby may have trouble fitting through your pelvis (cephalo-pelvic disproportion). This can cause birth injury to the baby. It can also increase the risk of a caesarean section.

And finally, any woman with high blood sugar has a greater chance ố developing infections, especially vaginal, bladder and kidney infections. Your physician will check your urine frequently to make sure that you do not have an infection. These problems rarely occur if blood sugar is observed routinely by your physician and the baby is monitored frequently through the pregnancy.

Please remember that by keeping your blood sugar in control you can prevent the potential complications of GDM. You can do this by using three simple tools: self blood 
glucose monitoring (SBGM), diet and exercise. SBGM is your key to success. It allows you to know immediately if you are maintaining adequate blood sugar control. The information obtained can be used to adjust your diet, exercise and/or insulin dosage, and of course prevent the complications of GDM.

Diet is the main component of treatment for GDM, and for most women it is effective in maintaining safe blood sugar levels. Dietary guidelines encourage a diet low in fat and high in complex carbohydrates and fiber with no added sugar. Typically the diet is based on the exchange system. Foods are divided into the 6 food groups: breads and starches, meats, vegetables, fruits and fruit juices, milk and milk products and fats and oils. Each exchange is equal to a portion size. For example one meat exchange is equal to one ounce of meat.

The meal plan ensures a proper distribution of protein, carbohyarates, and fats. Generally, a balanced diet for women with GDM consists of approximately 2,000 daily calories distributed among three meals and three snacks. The exact number of calories a woman needs varies according to her height, weight, and activity level and should be determined by the dietitian.

Adequate amounts of food are needed to properly nourish a growing baby, but the intake of food must be carefully monitored. Exercise, which lowers blood glucose and body fat 
levels, is also very important in the management of diabetes. Exercise can consist of a daily walk or a simple exercise routine as prescribed by your physician.

By monitoring blood sugar levels, the doctor will be able to determine whether the diet is effective or if insulin is required to maintain blood sugar control. For the majority of women the diet alone is effective; however, for others, the diet's effectiveness diminishes as the pregnancy progresses. An estimated 15 to 20 percent of women with GDM require insulin therapy as they continue to maintain their diet. Remember: by using SBGM, diet and exercise you may be able to avoid this.

For women with GDM, regular prenatal visits are especially important. For most of the pregnancy, prenatal care will not be that much different from that provided for non-diabetic women. In the last month of the pregnancy, the most critical time for women with GDM, the well-being of the baby must be carefuily monitored. Ultrasound is frequently done to tell whether the baby is growing properly. A nonstress test - a recording of the baby's heartbeat in response to movement - is also commonly performed once or twice a week during the last month of pregnancy.

If any of these observations give reason to be concerned, an early delivery may be recommended. At this time labor may be induced. This also occurs if you go beyond your delivery date. As confidence in the tests that assess fetal health 
and in the techniques to control blood sugar levels grows, more women will be allowed to deliver later, which will mean fewer inductions and fewer caesarean sections.

If you have been diagnosed with GDM you should look realistically at your need for treatment but also at how effective treatment can be in ensuring a healthy baby. By taking control of the diabetes, you can take control of the well-being of your baby. There is every reason not to relinquish the joy of pregnancy and to have a fine, healthy baby. 


\section{PLEASE NOTE:}

Copyrighted materials in this document have not been filmed at the request of the author. They are available for consultation, however, in the author's university library.

\section{These consist of pages:}

143-145 